\title{
ORC binds and remodels nucleosomes to specify MCM loading onto DNA
}

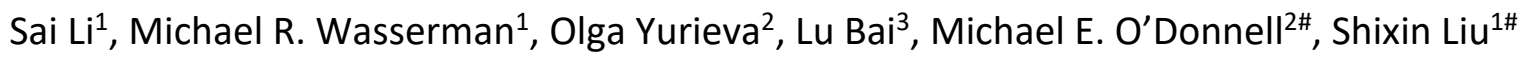

${ }^{1}$ Laboratory of Nanoscale Biophysics and Biochemistry, The Rockefeller University, New York, NY, USA

${ }^{2}$ Howard Hughes Medical Institute, Laboratory of DNA Replication, The Rockefeller University, New

York, NY, USA

${ }^{3}$ Center for Eukaryotic Gene Regulation, Department of Biochemistry \& Molecular Biology, Department of Physics, The Pennsylvania State University, University Park, PA, USA

\#Correspondence: odonnel@rockefeller.edu; shixinliu@rockefeller.edu

\begin{abstract}
Saccharomyces cerevisiae has been a faithful guide for study of eukaryotic DNA replication, as the numerous initiation and elongation proteins are conserved from yeast to human. However, there is a gap in our knowledge of why yeast uses a consensus DNA sequence at replication origins, while higher eukaryotes do not. The current study closes this gap. By direct single-molecule visualization, we show that the Origin Recognition Complex (ORC) searches for and stably binds nucleosomes, and that nucleosomes funtionalize ORC to load MCM helicase onto DNA, regardless of DNA sequence. Furthermore, we discover that ORC can remodel nucleosomes and expel $\mathrm{H} 2 \mathrm{~A}-\mathrm{H} 2 \mathrm{~B}$ histone dimers, a heretofore unexpected function. Thus ORC helps create a chromatin environment permissive to origin function. The finding that ORC binding to nucleosomes leads to MCM loading at any DNA sequence is likely to generalize, and that higher eukaryotes follow this same paradigm for origin selection
\end{abstract}

\section{INTRODUCTION}

Complete and accurate duplication of the genome is critical for the proliferation of all organisms (1). The basic mechanism for the initiation of DNA replication is shared by all three domains of cellular life (2). An "initiator" first binds to a genomic site known as the origin of replication, then recruits the replicative helicase that is responsible for unwinding parental DNA duplex and creating templates for daughter strand synthesis. In eukaryotes, multiple origins across the genome are licensed for firing once, and only once, per cell cycle and their firing follows a temporally controlled program (3). The eukaryotic initiator is known as the origin recognition complex (ORC), which consists of six highly conserved subunits Orc1-6 $(4,5)$. ORC works in concert with Cdc6 and Cdt1 to coordinate the loading of two Mcm2-7 helicase complexes onto the origin $(6,7)$, forming the pre-replication complex (pre-RC) that potentially becomes activated during the subsequent $S$ phase to produce bidirectional replication forks. In the model organism Saccharomyces cerevisiae (budding yeast), origins are located at a set of "replicator" positions known as autonomously replicating sequence (ARS) elements, each containing an AT-rich ARS consensus sequence (ACS) and other less conserved "B elements" (1). However, consensus ARS elements have yet to be found in higher eukaryotes including human (8). In fact, even in $S$. cerevisiae, the ARS and its internal ACS and B elements are not absolutely required for ORC binding, Mcm2-7 loading, or origin firing in vitro and in vivo $(7,9,10)$. These observations indicate that there 
exist yet other chromosomal features that enable licensing and firing of eukaryotic replication origins $(8,11)$.

One distinct challenge for ORC is the need to navigate through chromosomes predominantly packaged into nucleosomes (12), which influence multiple aspects of eukaryotic replication (13-15). Although still an area of active research, it is generally presumed that the nucleosome presents a barrier to ORC binding and origin activity, which must be overcome by DNA sequence or chromainremodeling enzymes. Consistent with the inhibitory effect of nucleosomes, it was shown that a nucleosome-free region (NFR) flanked by regularly positioned nucleosomes is a pronounced feature of ARS origin sites $(16,17)$. Notably, ORC binding and pre-RC assembly also play a direct role in shaping a local chromatin state permissive to replication initiation, often widening the NFR $(18,19)$. These studies suggest possible active participation of ORC in the formation of an adequate NFR for replication initiation. The interplay between ORC and nucleosomes is clearly a critical determinant for origin selection and function, but the molecular underpinning of this interplay remains incompletely understood.

Single-molecule studies using reconstituted replication proteins have greatly aided our understanding of origin recognition and pre-RC formation (20-22). However, these studies have not examined the effect of nucleosomes on ORC activity. In this work, we employ correlative singlemolecule fluorescence and force microscopy, complemented with biochemical assays and genomic analysis, to interrogate the dynamic behavior of ORC on nucleosomal DNA. We find that, contrary to expectation, ORC searches for and actively remodels nucleosomes in a chromatinzed environment, and that nucleosomes are the primary determinant of origin recognition and licensing, regardless of the ARS DNA sequence. This finding of ARS-independent, nucleosome-dependent origin selection makes the yeast system much more like that expected for higher eukaryotes, and expands the role of ORC to one that can also help form the chromatin environment for initiation.

\section{RESULTS}

\section{Direct observation of ORC interaction with nucleosomal DNA}

To perform the single-molecule studies we engineered a native $S$. cerevisiae origin sequence ARS1 (23) into the $\lambda$ phage genome (Supplementary Fig. 1A), generating a DNA template $\left(\lambda_{\text {ARS1 }}\right)$ that is biotinylated on both ends (Fig. 1A). We also purified the yeast Orc1-6 and Mcm2-7 complexes (referred to as ORC and MCM hereafter) (Supplementary Fig. 1B), as well as Cdc6 and Cdt1. To generate fluorescently labeled ORC for single-molecule visualization, we site-specifically attached a Cy3 fluorophore to the $\mathrm{N}$ terminus of the Orc1 subunit via a 12-residue peptide tag (S6), much smaller than the Halo-tag used in a recent single-molecule study (22). A single $\lambda_{\text {ARS1 }}$ molecule was tethered between a pair of streptavidin-coated beads in the microfluidic chamber of a dual-trap optical tweezers instrument also equipped with multicolor confocal fluorescence microscopy $(24,25)$ (Supplementary Fig. 1C). Upon moving the tethered DNA into a channel containing Cy3-ORC, Cdc6 and ATP, we observed ORC binding to DNA in real time (Fig. 1B). Consistent with previous results (21, 22), ORC-Cdc6 displayed diffusive behavior at non-ARS1 sites until it dissociated or encountered the ARS1 site, where the rapid diffusion behavior halted and, instead, ORC-Cdc6 resided stably (Fig. 1B). The distinctive behavior of ORC-Cdc6 at the engineered ARS1 site versus all other sites indicates that the $\lambda$ genome does not contain a strong ACS motif, consistent with sequence analysis using a published algorithm (26) (Supplementary Fig. 2). 
Next, we set out to examine the behavior of ORC on nucleosomal DNA. We juxtaposed a Widom601 nucleosome positioning sequence next to the ARS1 site and generated the $\lambda_{601 \text { ARS1 }}$ DNA template (Fig. 1C). We then loaded tethered $\lambda_{601 A R S 1}$ with histone octamers in situ by the histone chaperone Nap1. This method has been previously used to form nucleosomes $(14,27)$ and also confirmed by us via single-molecule pulling experiments (Supplementary Fig. 3). The octamers were fluorescently labeled with Cy5 for direct visualization. We observed nucleosomes formed both at the 601 site next to ARS1 and at other locations (Fig. 1D), which allowed us to compare ORC-nucleosome interaction at ARS1 versus non-ARS1 sites. Surprisingly, we found that in the vast majority of cases ORC stably associated with the nucleosome, regardless of whether it was located adjacent to the ARS1 site or was at a non-ARS1 site (Fig. 1D). This is in contrast to the discrimination by ORC between ARS1 and non-ARS1 sites on non-nucleosomal DNA (Fig. 1E, F). Nucleosome targeting by ORC can conceivably be achieved by either a three-dimensional (3D) search (direct binding from solution) or a one-dimensional (1D) search (sliding along the DNA from a non-nucleosomal site). Indeed, we observed both modes in our data (Fig. 1D), with 3D search being the more dominant mode under our experimental conditions (Fig. 1G). These results suggest that ORC preferentially binds to nucleosomes when in a chromatinized DNA environment.

\section{Nucleosome-bound ORC mediates pre-RC assembly}

Next we asked whether the stable association of ORC with nucleosomes can lead to pre-RC formation. To this end, we engineered an S6-Mcm3 yeast strain and purified MCM complexes labeled with either a Cy3 or LD650 fluorophore. Using a mixture of Cy3-MCM and LD650-MCM along with unlabeled ORC, Cdc6 and Cdt1, we observed that MCM double hexamers can assemble on DNA and sustain a high-salt wash (Supplementary Fig. 4). These results further validate the functionality of our replication protein reagents. We then used LD650-MCM to visualize helicase loading onto nucleosomal DNA by ORC. Cy3nucleosome-bound $\lambda_{601 A R S 1}$ was incubated with ORC, Cdc6, LD650-MCM, Cdt1, and ATP. Strikingly, we found that MCM exclusively colocalized with nucleosomes (Fig. 2A, B). Detection of the MCM signal strictly requires the presence of ORC (i.e. there were zero MCM-nucleosome colocalization events observed in the absence of ORC). To confirm ORC-mediated recruitment of MCM to nucleosomes, we performed three-color experiments with AlexaFluor488 (A488)-labeled MCM, LD650-ORC, and Cy3nucleosome (Fig. 2C). Indeed we detected colocalization of all three fluorescence signals (Fig. 2D). The intermittent disappearance of the A488 signal was likely due to fluorophore blinking as it was not observed in the two-color experiments using LD650-labeled MCM (Fig. 2B). These results suggest that, independent of the DNA sequence, nucleosome positioning provides instructive information for pre-RC assembly.

\section{ORC is a nucleosome remodeler that evicts $\mathrm{H} 2 \mathrm{~A}-\mathrm{H} 2 \mathrm{~B}$ dimers}

Upon examining the colocalization events of LD650-labeled ORC and nucleosomes containing Cy3labeled $\mathrm{H} 2 \mathrm{~B}$, we made the unexpected finding that the $\mathrm{H} 2 \mathrm{~B}$ fluorescence signal often disappeared after a few minutes of ORC engagement (Fig. 3A-D). We can rule out the possibility that the loss of fluorescence is due to photobleaching, because the H2B signal was stable in the absence of ORC (Fig. $3 \mathrm{E})$. It is also unlikely that the loss of $\mathrm{Cy} 3$ signal was caused by fluorescence resonance energy transfer between Cy3-H2B and LD650-ORC, as we did not observe a corresponding increase in the LD650-ORC intensity (Fig. 3A, B). Therefore, the most plausible explanation is that $\mathrm{H} 2 \mathrm{~B}$ was evicted from the nucleosome by ORC. This phenomenon was observed at both ARS1 (Fig. 3A) and non-ARS1 (Fig. 3B) 
nucleosome sites with comparable eviction probabilities (Fig. $3 \mathrm{C}$ ). Overall we found that $40 \%$ of $\mathrm{H} 2 \mathrm{~B}$ with a colocalized ORC were ejected and that the average time between ORC binding and $\mathrm{H} 2 \mathrm{~B}$ dissociation is $202 \pm 22 \mathrm{~s}$. Similar eviction efficiency (45\%) and kinetics (173 $\pm 29 \mathrm{~s}$ ) were observed when we monitored the fate of $\mathrm{H} 2 \mathrm{~A}$ using Cy3-labeled H2A (Fig. 3D, F).

In contrast, by labeling histone $\mathrm{H} 3$ and simultaneously monitoring $\mathrm{ORC}$ and $\mathrm{H} 3$ fluorescence signals, we found that virtually all $\mathrm{H} 3$ molecules that had colocalized with ORC remained bound to DNA within the observation window (Fig. 3G, H). Therefore, we concluded that ORC remodels nucleosomes by selectively removing $\mathrm{H} 2 \mathrm{~A}-\mathrm{H} 2 \mathrm{~B}$ dimers rather than disassembling the entire nucleosome. The $\mathrm{H} 2 \mathrm{~A}-$ H2B eviction efficiency was not affected by the tension applied to the tether (Supplementary Fig. 5A), which was kept low $(<2.5 \mathrm{pN})$ during these experiments to minimize any destabilizing effect on the nucleosome. In most cases, ORC was retained at the nucleosomal site after evicting $\mathrm{H} 2 \mathrm{~A}-\mathrm{H} 2 \mathrm{~B}$ (Supplementary Fig. 5B-D), presumably staying associated with the remaining $(\mathrm{H} 3-\mathrm{H} 4)_{2}$ tetramer. Next we assessed the role of nucleotides in ORC's histone eviction activity. Omitting ATP from the single-molecule assay abolished ORC loading on DNA altogether, consistent with previous biochemical results $(4,28)$. Replacing ATP with its non-hydrolyzable analog AMPPNP enabled ORC binding to nucleosomal DNA, but drastically diminished the H2A-H2B ejection efficiency (Fig. 3D), indicating that ATP hydrolysis is involved in $\mathrm{H} 2 \mathrm{~A}-\mathrm{H} 2 \mathrm{~B}$ eviction by $\mathrm{ORC}$.

\section{ORC alters nucleosomal DNA accessibility}

Our single-molecule results raised the question of whether ORC binding renders the nucleosomal DNA more accessible due to $\mathrm{H} 2 \mathrm{~A}-\mathrm{H} 2 \mathrm{~B}$ dissociation, or less accessible due to ORC occlusion. To better understand the local configuration of ORC-adjacent nucleosomal DNA, we performed a restriction enzyme accessibility assay with a reconstituted 601 mononucleosome linked to an ARS1 element (Fig. 4A). We first evaluated the cleavage efficiency of Banl, whose restriction site is located $18 \mathrm{bp}$ from the ARS1-proximal nucleosomal DNA end. We found that incubation with ORC and ATP led to significantly enhanced Banl cleavage compared to control conditions (Fig. 4B, Supplementary Fig. 6A), suggesting that the Banl site became more exposed upon ATP-dependent nucleosome remodeling by ORC. Interestingly, when we performed the same assay with a different enzyme BsiWI whose restriction site is located close to the nucleosome dyad, we did not detect a similar enhancement conferred by ORC and ATP (Fig. 4C, Supplementary Fig. 6B). These results are consistent with the notion that ORC selectively removes $\mathrm{H} 2 \mathrm{~A}-\mathrm{H} 2 \mathrm{~B}$ dimers, making the outer turn of nucleosomal DNA more accessible while leaving the inner turn bound to the $\left(\mathrm{H} 3-\mathrm{H}_{4}\right)_{2}$ tetramer protected. In this regard, ORC is distinctive from other well-known remodelers such as ISW1a, which slides the entire histone octamer relative to the DNA (14). As expected, ISW1a enhanced both Banl and BsiWI cleavage in our assay (Fig. 4B-C, Supplementary Fig. 6).

\section{ORC changes histone content within nucleosomes genome-wide}

To investigate if ORC-induced nucleosome remodeling observed in vitro also occurs in the cell, we analyzed in vivo nucleosome composition over genome-wide ORC binding sites based on published datasets. First, we identified 1,000 top-ranked Orc1 binding sites based on the yeast Orc1 ChIP-seq data (17), and sorted them into two groups based on their peak intensities. Next we analyzed the MNase-histone ChIP-seq data (29). In this dataset, the MNase-seq signal ("input") reflects the degree of protection against micrococcal nuclease digestion at a given genomic site; the subsequent $\mathrm{H} 2 \mathrm{~B} / \mathrm{H} 4$ ChIP-seq signal ("IP") reflects the level of $\mathrm{H} 2 \mathrm{~B}$ or $\mathrm{H} 4$ in the protected particles at the corresponding 
site. Nucleosome composition can thus be evaluated by calculating the ratio between IP and input (Fig. 5A). Over the highly ranked Orc1 sites, the average $\mathrm{H} 4$ content is centered around 1-the normalized genome-average level generated from the IP/input values for 10,000 randomly selected sites. Significantly, the average H2B content at strong Orc1 sites is depleted to 0.6-0.7 (Fig. 5B-D, Supplementary Fig. 7). In contrast, over the lower ranked Orc1 sites (weak ORC binding or falsepositive sites), the $\mathrm{H} 2 \mathrm{~B}$ and $\mathrm{H} 4$ contents have very similar distributions. This analysis supports the model that strong ORC binding within the yeast genome induces selective $\mathrm{H} 2 \mathrm{~A}-\mathrm{H} 2 \mathrm{~B}$ depletion in the nearby nucleosomes.

\section{DISCUSSION}

\section{Nucleosomes dominate over ARS in defining ORC function}

The prevailing model for origin selection in budding yeast takes a DNA-centric view in that ARS, and especially the ACS element within ARS, largely dictates where ORC binds in the genome (1).

Nonetheless, in vitro studies demonstrate that these elements are mechanistically required for pre-RC formation or to initiate replication $(7,9)$. For example, the MCM loading efficiency was indistinguishable between wild type and ACS-deleted ARS1 sequences unless competitor DNA was added (7). Structures of ORC bound to ACS show that an insertion helix (IH) of Orc4 is responsible for their interaction $(30,31)$. A recent study showed that cells harboring mutant ORC with the IH removed were surprisingly still viable, and that initiation instead occurred at different nucleosome-free regions of the genome that lack an ACS (10). Furthermore, the yeast genome contains vastly more potential ACS motifs than functional origins (32). Given these observations, it has been postulated that other chromatin features are involved in determining eukaryotic origins $(8,11)$.

By imaging ORC's behavior on nucleosomal DNA in real time, our work provides clear evidence that ORC preferentially binds to nucleosome sites rather than non-nucleosomal DNA-independent of a nearby strong ACS motif-and that this interaction is functionally relevant as it leads to MCM loading at nucleosomal sites (Fig. 6A). The influence of nucleosomes on replication initiation has been previously investigated (33), but mainly reported as a secondary mechanism to enhance the DNAencoded origin specificity by targeting ORC to ARS instead of other DNA sequences that become occupied by nucleosomes $(14,15)$. Here we show that nucleosomes-in and of themselves-represent the primary instructive code that defines eukaryotic replication origins. The main additional requirement thus becomes the existence of a NFR next to the ORC-bound nucleosome for helicase loading. Given the highly conserved nature of replication initiation factors, we presume that these findings will generalize to higher eukaryotes, just as the many other findings in the S. cerevisiae system has done up to the present. Thus, the present work potentially unifies the mechanism for origin selection across eukaryotic species, many of which, including metazoans, appear to lack a consensus DNA motif at their origins (34).

\section{Why origin selection does not occur at every nucleosome?}

Our findings suggest that MCM loading could in principle occur at any nucleosome. However, as mentioned above, in the cell these events are likely limited to the periphery of NFRs because the bulk of the genome is packaged into chromatin that would prevent ORC and MCM from binding to DNA. As a corollary, there is evidence that origins located within the tightly packed heterochromatin fire later in the S phase compared to those in the more open euchromatin (35). The ARS sequence inherently excludes nucleosomes and positions them at its boundaries, thereby creating a NFR for ORC to bind 
and associate with the nearby nucleosome. As such, ACS and the ARS elements around it may confer origin specificity in yeast by facilitating ORC binding to nucleosomes that are proximal to the ACS sequence. This view reconciles the strong nucleosome preference by ORC that we observed in vitro and the requirement of ACS/ARS elements for yeast origins in vivo.

\section{Why did yeast evolve ARS elements?}

One may ask why some yeast species developed a consensus origin sequence. The slight advantage that the ACS/ARS sequence provides to ORC binding to DNA lacking nucleosomes, along with the binding of ORC to a nucleosome that is adjacent to the ACS, appears to direct pre-RC licensing of origins in yeast to specific positions of the genome, located between transcribed genes instead of at the NFRs within transcriptionally active zones. Thus we speculate that organisms that replicate quickly and have a small genome size such as $S$. cerevisiae might have needed to specify origin licensing to regions outside of active transcription units to lower the probability of transcriptional interference with origin function. Metazoans, which have much larger genomes, may have evolved other mechanisms to circumvent or tolerate transcriptional interference, and thus did not need to evolve a specific origin consensus sequence for positioning nucleosomes away from transcription units (36).

\section{Implications of ORC's chromatin remodeling activity}

It is known that ORC and MCM loading correlate with widening of the NFR at an ARS element $(18,19)$. We show here that ORC can eject $\mathrm{H} 2 \mathrm{~A}-\mathrm{H} 2 \mathrm{~B}$, revealing a new nucleosome-remodeling acitivty of ORC. But whether the documented expansion of NFR in the ARS region is due to $\mathrm{H} 2 \mathrm{~A}-\mathrm{H} 2 \mathrm{~B}$ ejection or "rolling" the nucleosome away from the origin has not been known. We observed in the current study that about half of ORC binding events lead to ejection of $\mathrm{H} 2 \mathrm{~A}-\mathrm{H} 2 \mathrm{~B}$ from a nucleosome (Fig. 6B). Consistent with ORC-mediated $\mathrm{H} 2 \mathrm{~A}-\mathrm{H} 2 \mathrm{~B}$ eviction observed in the single-molecule experiments, our genomic analyses show that strong $\mathrm{ORC}$ binding sites correlate with a deficiency of $\mathrm{H} 2 \mathrm{~B}$ relative to $\mathrm{H} 4$. This raises new questions on whether $\mathrm{ORC}$-mediated eviction of $\mathrm{H} 2 \mathrm{~A}-\mathrm{H} 2 \mathrm{~B}$ results in nucleosome editing where other histone variants replace $\mathrm{H} 2 \mathrm{~A}-\mathrm{H} 2 \mathrm{~B}$, or whether it is simply a means to expand a NFR for pre-RC assembly in a fully licensed origin. Moreover, ORC is known to bind nucleosomes via the bromoadjacent homology $(\mathrm{BAH})$ domain of $\operatorname{Orc1}(37,38)$. However, even when the BAH domain is deleted, $\mathrm{ORC}^{\triangle \mathrm{BAH}}$ still binds to nucleosomes (39). Thus, there are likely multiple linkages between ORC and the nucleosome that allow ORC to load MCMs and/or to remodel nucleosomes.

While we have shown that ORC-nucleosome interaction can lead to MCM loading, other nucleosome-binding factors may be involved to generate a chromatin environment permissive to activating a licensed pre-RC into a functional replisome (14). Future studies, particularly singlemolecule observations and high-resolution genome mapping assays (40), will be needed to address how the nucleosome-based origin code is fine-tuned by regulatory inputs such as epigenetic features of the chromatin $(37,41)$, and how the ORC-nucleosome interplay maintains the proper origin firing program and chromosomal stability (42). 


\section{METHODS}

\section{Protein expression and purification}

S6-ORC

A recombinant strain of yeast co-expressing the six subunits of ORC, having an $\mathrm{S} 6$ tag for fluorescent labeling at the $\mathrm{N}$ terminus of Orc1, was constructed as follows: We used either an Orc1 gene with an Nterminal 3xFlag (wt ORC) or further modified the Orc1 subunit gene by insertion of DNA encoding the "S6" peptide (GDSLSWLLRLLN) at the N terminus (S6-ORC) (43). The six subunits of ORC complex were cloned into integration vectors having the galactose inducible Gal1/10 bidirectional promotor for induction by galactose and were cloned and integrated into the genome of strain 0Y001 (ade2-1 ura31 his311,15 trp11 leu23,112 can1100 bar1D, MATa pep4øKANMX6), a strain constructed from W303 (44). The order of integration was: (1) Genes encoding 3×Flag-Orc1 or S6-3×Flag-Orc1, and Orc3 (both cloned into pRS404/GAL); (2) genes encoding Orc4 and Orc5 (both cloned into pRS405/GAL); (3) the gene encoding Orc2 (cloned into pRS403/GAL); and (4) the gene encoding Orc6 (cloned into pRS402/GAL). The wt and S6-ORC overexpression strains were constructed by integrating the expression plasmids described above in the yeast genome. Both wt ORC and S6-ORC were purified by the same procedure below.

One liter of S6-ORC cells were grown under selection at $30{ }^{\circ} \mathrm{C}$ in SC glucose, then split into twelve 2-L fluted flasks, each containing $1 \mathrm{~L}$ of YP-glycerol media and grown to an $\mathrm{OD}_{600}$ of 0.4 at $30{ }^{\circ} \mathrm{C}$, arrested with $\alpha$-factor $(50 \mu \mathrm{g} / \mathrm{L})$ for $2 \mathrm{~h}$, and then induced for $3 \mathrm{~h}$ upon addition of $20 \mathrm{~g} / \mathrm{L}$ of galactose. Cells were harvested by centrifugation, resuspended in a minimal volume of $20 \mathrm{mM} \mathrm{HEPES} \mathrm{pH} \mathrm{7.6,}$ $1.2 \%$ polyvinyl pyrrolidone, and protease inhibitors (Sigma-Aldrich \#5056489001) and $0.5 \mathrm{mM}$ PMSF, then snap frozen by dripping into liquid nitrogen. Purification of the S6-ORC complex was performed by lysis of $12 \mathrm{~L}$ of frozen cells using two SPEX cryogenic grinding mills (6970 EFM). Ground cells were thawed and debris removed by centrifugation $\left(19,000 \mathrm{rpm}\right.$ in an SS34 rotor for $2 \mathrm{~h}$ at $\left.4{ }^{\circ} \mathrm{C}\right)$; then the supernatant was applied to a 1-mL anti-Flag M2 affinity column (Sigma) equilibrated in buffer $\mathrm{H}$ (50 mM HEPES pH 7.5, $250 \mathrm{mM}$ potassium glutamate, $1 \mathrm{mM}$ EDTA, 10\% glycerol). Elution was in buffer $\mathrm{H}$ containing $0.15 \mathrm{mg} / \mathrm{mL} 3 \times$ Flag peptide (EZBiolab). Peak fractions were diluted with 2 volumes of buffer $\mathrm{H}$ and loaded onto a 1-mL SP HP column (GE Healthcare) and washed with buffer C (50 mM HEPES pH 7.5, $100 \mathrm{mM} \mathrm{KOAc)}$. Elution was with an 8-mL linear gradient of 100-600 mM KOAc in $50 \mathrm{mM}$ HEPES $\mathrm{pH}$ 7.5. The S6-ORC complex eluted at approximately $400 \mathrm{mM}$ KOAc. Protein concentration of column fractions was determined by Bradford reagent (Bio-Rad), and stored at $-80^{\circ} \mathrm{C}$.

\section{S6-MCM}

Recombinant strains of yeast that co-expressed the six subunits of $\mathrm{Mcm} 2-7$ complex having an $\mathrm{N}$ terminal S6-3×Flag tag for fluorescent labeling (S6-MCM), or only a 3×Flag tag on Mcm3 (wt MCM) were constructed as follows. The six subunits of $\mathrm{Mcm}$ 2-7 were cloned into integration vectors, each having the galactose inducible Gal1/10 bidirectional promotor for induction by galactose. The vectors were then integrated into the genome of strain OY001. Genes encoding Mcm4 and 3×Flag-S6-Mcm3 (or 3xFlag-Mcm3) were cloned into pRS404/GAL (Trp); genes encoding Mcm6 and Mcm7 were cloned into pRS405/GAL (Leu); the gene encoding Mcm2 was cloned into pRS403/GAL (His); and the Mcm5 gene was cloned into pRS406/GAL (Ura). The vectors were integrated in OY001 in the order described above to yield S6-MCM (or wt MCM). S6-MCM cells were grown and induced as described for S6-ORC. Purification of S6-MCM complex was performed by lysis of $12 \mathrm{~L}$ of frozen cells with a SPEX cryogenic 
grinding mill (6970 EFM). Ground cells were thawed and debris removed by centrifugation (12,500 rpm in a SLC-1500 rotor at $4{ }^{\circ} \mathrm{C}$ ). The clarified extract was applied to a 3-mL anti-Flag $\mathrm{M} 2$ affinity column (Sigma) equilibrated in buffer M (50 mM HEPES pH 7.5, $100 \mathrm{mM}$ potassium glutamate, $2 \mathrm{mM}$ DTT, 1 $\mathrm{mM}$ EDTA, $10 \mathrm{mM} \mathrm{Mg}(\mathrm{OAc})_{2}$, $0.5 \mathrm{mM}$ ATP, 10\% glycerol). The column was washed with $25 \mathrm{~mL}$ buffer $\mathrm{M}$, then eluted with buffer $\mathrm{M}$ containing $0.15 \mathrm{mg} / \mathrm{mL} 3 \times$ Flag peptide (EZBiolab). Protein concentration of column fractions was determined by Bradford reagent (Bio-Rad), then aliquoted, snap frozen in liquid $\mathrm{N}_{2}$ and stored at $-80^{\circ} \mathrm{C}$.

\section{Cdc6}

An E. coli optimized gene sequence for expression of S. cerevisiae Cdc6 in E. coli (a generous gift of Dr. Megan Davey, Western Univ., London, Ontario, CA) was cloned into pET11 (Novagen). The Cdc6 gene was then subcloned into pGEX-6P-1 (GeneScript) to provide a N-terminal GST tag with a PreScission protease site which we refer to as pGST-Cdc6 PST/P. E. coli BL21(DE3) cells were transformed with the pGST-Cdc6 PST/P plasmid and cells were grown in LB $+100 \mu \mathrm{g} / \mathrm{mL}$ ampicillin at $37^{\circ} \mathrm{C}$ with shaking until reaching an OD of 0.49 , at which time the culture temperature was quickly reduced to $14{ }^{\circ} \mathrm{C}$ by shaking in an ice bath. Then IPTG (1 mM) and 0.2\% ethanol were added to induce GST-Cdc6 expression for $24 \mathrm{~h}$ at $15{ }^{\circ} \mathrm{C}$. Cells were harvested by low speed centrifugation at $4{ }^{\circ} \mathrm{C}$, and the cell pellet was resuspended in buffer $\mathrm{G}(50 \mathrm{mM}$ Tris-HCl pH 7.5, 1mM EDTA, 10\% glycerol) plus $30 \mu \mathrm{M}$ spermidine and $500 \mathrm{mM}$ $\mathrm{NaCl}$. Cells were lysed by French Press and the lysate was clarified by centrifugation at 14,000 rpm for 1 $\mathrm{h}$ at $4{ }^{\circ} \mathrm{C}$. The supernatant was loaded onto a $5-\mathrm{mL}$ glutathione column (GE Healthcare), followed by washing with 20 column volumes of buffer $\mathrm{G}$ plus $300 \mathrm{mM} \mathrm{NaCl}$. Elution was performed using $25 \mathrm{~mL}$ of $20 \mathrm{mM}$ Tris- $\mathrm{HCl}$ pH 8.0, 1mM EDTA, 10\% glycerol, $47 \mathrm{mM}$ glutathione and $300 \mathrm{mM} \mathrm{NaCl}$. Fractions of 1 $\mathrm{mL}$ were collected and analyzed by SDS PAGE. Fractions containing GST-Cdc6 were treated with $200 \mathrm{U}$ PreScission protease (ThermoFisher) for $2 \mathrm{~h}$ on ice, then were diluted with buffer A ( $20 \mathrm{mM} \mathrm{HEPES} \mathrm{pH}$ 7.5, $1 \mathrm{mM}$ EDTA, 10\% glycerol) to a conductivity of $85 \mathrm{uS} / \mathrm{CM}$ and loaded onto an 8-mL SP-Sepharose column (Sigma). Cdc6 was eluted in 20-mL steps of buffer A containing either $0.2 \mathrm{M}, 0.3 \mathrm{M}, 0.4 \mathrm{M}, 0.5$ $\mathrm{M} \mathrm{NaCl}$. Fractions were analyzed for Cdc6 by SDS PAGE, and fractions containing Cdc6 were pooled and passed through a 2-mL GST column to remove remaining GST contaminants. Protein concentration was determined by Bradford reagent (Bio-Rad), then aliquoted, snap frozen in liquid $\mathrm{N}_{2}$ and stored at $80^{\circ} \mathrm{C}$.

\section{Cdt1}

Cdt1 was cloned into a pET16b vector followed by replacement of the Ncol/Ndel region with insertion of a DNA segment encoding a $3 \times$ Flag tag. E. coli was transformed with the pFlag-Cdt1-pET plasmid and cells were grown in $\mathrm{LB}+100 \mu \mathrm{g} / \mathrm{mL}$ ampicillin at $37^{\circ} \mathrm{C}$ with shaking until reaching an $\mathrm{OD}$ of 0.6 , at which time the culture temperature was quickly reduced to $15^{\circ} \mathrm{C}$ by shaking in an ice bath. Then IPTG $(1 \mathrm{mM})$ was added to induce Cdt1 expression for $10 \mathrm{~h}$ at $15^{\circ} \mathrm{C}$. Cells were then harvested by low speed centrifugation at $4{ }^{\circ} \mathrm{C}$, and the cell pellet was resuspended in $50 \mathrm{~mL}$ of buffer $\mathrm{B}(50 \mathrm{mM} \mathrm{HEPES} \mathrm{pH} \mathrm{7.5,} 1$ mM EDTA, 2 mM DTT, 2 mM MgCl $2,10 \%$ glycerol) plus $800 \mathrm{mM} \mathrm{NaCl}$, and lysed by French Press. Cell lysate was clarified by centrifugation at $14,000 \mathrm{rpm}$ for $1 \mathrm{~h}$ at $4{ }^{\circ} \mathrm{C}$. The supernatant was treated with $1.5 \mathrm{~mL}$ Flag beads (Sigma) for $1 \mathrm{~h}$ with gentle agitation, then packed into a 5-mL GE C column equilibrated in buffer $B$ at $4{ }^{\circ} \mathrm{C}$. Cdt1 was eluted with buffer $B$ containing $175 \mathrm{mM} \mathrm{NaCl}$ and $0.2 \mathrm{mg} / \mathrm{mL}$ $3 \times$ Flag peptide. The preparation was then diluted 2-fold with buffer $B$ to reduce conductivity, applied to a 1-mL Heparin agarose column (Sigma), and eluted with a 10-mL linear gradient of $100 \mathrm{mM} \mathrm{NaCl}$ to 
$500 \mathrm{mM} \mathrm{NaCl}$ in buffer B. Protein concentration of column fractions was determined by Bradford reagent (Bio-Rad), then aliquoted, snap frozen in liquid $\mathrm{N}_{2}$ and stored at $-80^{\circ} \mathrm{C}$.

\section{Nap1}

S. cerevisiae Nap1 was expressed in E. coli from the gene inserted into pGEX-6P-1, a kind gift of Dr. Aaron Johnson (U. Colorado, Denver). The GST-Nap1 was purified essentially as described $(28,45)$, except for passage of the final prep through a GST column (ThermoFisher). Briefly, the pGEX-GST-Nap1 expression plasmid was transformed into E. coli BL21 (DE3) cells, and $6 \mathrm{~L}$ were grown in LB plus 100 $\mathrm{mg} / \mathrm{mL}$ ampicillin to an OD of 0.5 at which time the culture temperature was quickly reduced to $15^{\circ} \mathrm{C}$ by shaking in an ice bath. Then IPTG $(1 \mathrm{mM})$ was added to induce Nap1 expression for $10 \mathrm{~h}$ at $15^{\circ} \mathrm{C}$. Cells were harvested by low speed centrifugation at $4{ }^{\circ} \mathrm{C}$, and the cell pellet was resuspended in 100 $\mathrm{mL}$ of PBS (ThermoFisher) plus $500 \mathrm{mM} \mathrm{NaCl}, 1.5 \mathrm{mM}$ DTT, $1 \mathrm{mM}$ EDTA, $30 \mathrm{mM}$ spermidine and $0.5 \%$ Triton100. Cells were lysed by French Press, and the cell lysate was clarified by centrifugation. The supernatant was loaded onto a 4-mL GST column (GE Healthcare) equilibrated in PBS containing $1 \mathrm{mM}$ EDTA, $0.1 \mathrm{mM}$ DTT, $0.1 \mathrm{mM}$ PMSF, 0.5\% Triton X-100, 10\% glycerol, and $350 \mathrm{mM} \mathrm{NaCl}$. Elution was with $50 \mathrm{mM}$ Tris- $\mathrm{HCl}$ pH 8.0, 1 mM EDTA, $5 \mathrm{mM}$ DTT, $300 \mathrm{mM} \mathrm{NaCl}, 10 \%$ glycerol and $47 \mathrm{mM}$ glutathione. Fractions of $2 \mathrm{~mL}$ were collected and analyzed by SDS PAGE for presence of Nap1. Fractions containing Nap1 were pooled and $100 \mathrm{U}$ of PreScission protease (ThermoFisher) was added prior to dialysis overnight against buffer C (20 mM Tris pH 7.5, 1 mM EDTA, 1mM DTT, $150 \mathrm{mM} \mathrm{NaCl}, 10 \%$ glycerol). Twenty eight $\mathrm{ml}$ of the dialysate was then loaded onto a 1-mL MonoQ column and eluted with a 20-mL gradient from $150 \mathrm{mM}$ to $1 \mathrm{M} \mathrm{NaCl}$ in buffer C. Peak fractions containing Nap1 were pooled and then passed over a GST column to remove any contaminating GST tag and GST-PreScission protease. Protein concentration of column fractions was determined by Bradford reagent (Bio-Rad), then aliquoted, snap frozen in liquid $\mathrm{N}_{2}$ and stored at $-80^{\circ} \mathrm{C}$.

\section{Histone octamer}

Recombinant Xenopus laevis histones and histone mutants were purified as previously described (46). Briefly, histones were expressed in BL21 (DE3) cells. Histones were extracted from inclusion bodies under denaturing conditions and purified through Q FF and SP FF columns (GE Healthcare). Histone octamers were then refolded by dialysis and purified by gel filtration using a Superdex $20010 / 300 \mathrm{GL}$ column.

\section{Fluorescent labeling of proteins}

To label S6-ORC and S6-MCM, the protein, Sfp synthase and dye-CoA (dye = Cy3, LD650, or A488) were incubated at a 1:2:5 molar ratio for $1 \mathrm{~h}$ at room temperature in the presence of $10 \mathrm{mM} \mathrm{MgCl} 2$. Excess dyes and Sfp were removed by a 100-kDa Amicon spin filter. The sample was then buffer-exchanged into $50 \mathrm{mM}$ HEPES pH 7.5, $100 \mathrm{mM}$ KOAc, $250 \mathrm{mM}$ potassium glutamate, $1 \mathrm{mM}$ EDTA, 10\% glycerol, and $10 \mathrm{mM} \mathrm{MgSO}_{4}$ for S6-ORC, or $50 \mathrm{mM} \mathrm{HEPES} \mathrm{KOH} \mathrm{pH} \mathrm{7.5,} 100 \mathrm{mM} \mathrm{KOAc,} 2 \mathrm{mM}$ DTT, $10 \mathrm{mM}$ $\mathrm{Mg}(\mathrm{OAc})_{2}, 0.5 \mathrm{mM}$ ATP and $10 \%$ glycerol for S6-Mcm2-7. The final products were aliquoted, flash frozen, and stored at $-80^{\circ} \mathrm{C}$.

To label histones, single-cysteine constructs H2A K120C, H2B T49C, and H3 G33C+C110A were generated by site-directed mutagenesis. All histones were purified and labeled as previously described (46). Briefly, they were incubated with Cy3/Cy5 maleimide (GE Healthcare) at 1:5 molar ratio in a labeling buffer (20 mM Tris- $\mathrm{HCl} \mathrm{pH} \mathrm{7.0,} 7 \mathrm{M}$ Guanidine-HCl, $5 \mathrm{mM}$ EDTA, and 1.25 mM TCEP) for $4 \mathrm{~h}$ at 
room temperature. The labeling reaction was quenched with $80 \mathrm{mM} \beta$-mercaptoethanol. Excess dyes were removed by dialysis with a 10-kDa Amicon spin filter.

\section{Preparation of DNA templates}

DNA for single-molecule experiments

To generate $\lambda_{\text {ARS1 }}$ DNA, a 501-bp DNA fragment containing the 185-bp Stillman minimum ARS1 sequence (47)

(TCGAGAAGCAGGTGGGACAGGTGAACTTTTGGATTGGAACTCGATTTCTGACTGGGTTGGAAGGCAAGAGAGC CCCGAAAGCTTACATTTTATGTTAGCTGGTGGACTGACGCCAGAAAATGTTGGTGATGCGCTTAGATTAAATGGC GTTATTGGTGTTGATGTAAGCGGAGGTGTGGAGACAAATGGTGTAAAAGACTCTAACAAAATAGCAAATTTCGT CAAAAATGCTAAGAAATAGGTTATTACTGAGTAGTATTTATTTAAGTATTGTTTGTGCACTTGCCTGCAGGCCTTT TGAAAAGCAAGCATAAAAGATCTAAACATAAAATCTGTAAAATAACAAGATGTAAAGATAATGCTAAATCATTT GGCTTTTTGATTGATTGTACAGGAAAATATACATCGCAGGGGGTTGACTTTTACCATTTCACCGCAATGGAATCA AACTTGTTGAAGAGAATGTTCACAGGCGCATACGCTACAATGACCCGATTCTTG; the 185-bp ARS1 sequence is underlined; bold sequences represent B3, B2, B1 and ACS elements) was amplified from the yeast chromosome (S288C_ChrIV BK0069382: 462,279-462,787) and inserted into $\lambda$ DNA (Roche, Cat\# 11558706910) with Xhol and Nhel restriction enzymes (New England BioLabs). The product was then packaged into phage particles using phage extract (MaxPlax, Epicentre). Plagues were generated on LE392 E. coli bacterial lawns (Epicentre) and screened for the ARS1 insert. A screened plaque was used as a phage source to purify $\lambda_{\text {ARS1 }}$ DNA by lytic growth (48). The final $\lambda_{A R S 1}$ DNA is 47,822 bp in length and the ARS1 site is located 33,499-33,999 bp from the left end of the the phage genome. To create a terminally biotinylated $\lambda_{\text {ARS1 }}$ DNA, the 12-base $5^{\prime}$ overhang on each end was filled in with a mixture of unmodified and biotinylated nucleotides by the exonuclease-deficient DNA polymerase I Klenow fragment (New England BioLabs). The reaction was conducted by incubating $10 \mathrm{nM} \lambda_{\text {ARS1 }}$ DNA, $33 \mu \mathrm{M}$ each of dGTP/dATP/biotin-11-dUTP/biotin-14-dCTP (Thermo Fisher), and 5 U Klenow in 1× NEB2 buffer at $37^{\circ} \mathrm{C}$ for $45 \mathrm{~min}$, followed by heat inactivation at $75^{\circ} \mathrm{C}$ for $20 \mathrm{~min}$. The DNA was then ethanol precipitated overnight at $-20^{\circ} \mathrm{C}$ in $2.5 \times$ volume cold ethanol and $300 \mathrm{mM} \mathrm{NaOAc} \mathrm{pH}$ 5.2. Precipitated DNA was recovered by centrifugation at $20,000 \times \mathrm{g}$ at $4{ }^{\circ} \mathrm{C}$ for $15 \mathrm{~min}$. After removing the supernatant, the pellet was air-dried, resuspended in TE buffer (10 mM Tris- $\mathrm{HCl}$ pH 8.0, $1 \mathrm{mM}$ EDTA) and stored at $4{ }^{\circ} \mathrm{C}$.

To generate biotinylated $\lambda_{601 A R S 1}$ DNA, a 338-bp DNA fragment containing a 601 nucleosome positioning sequence and a juxtaposed ARS1 sequence (TCGAGACAGGATGTATATATCTGACACGTGCCTGGAGACTAGGGAGTAATCCCCTTGGCGGTTAAAACGCGGG GGACAGCGCGTACGTGCGTTTAAGCGGTGCTAGAGCTGTCTACGACCAATTGAGCGGCCTCGGCACCGGGATTC TCCAGAAAATAGCAAATTTCGTCAAAAATGCTAAGAAATAGGTTATTACTGAGTAGTATTTATTTAAGTATTGTT TGTGCACTTGCCTGCAGGCCTTTTGAAAAGCAAGCATAAAAGATCTAAACATAAAATCTGTAAAATAACAAGAT GTAAAGATAATGCTAAATCATTTGGCTTTTTGATTGATTGTG; the 601 sequence is shown in italics; the ARS1 sequence is underlined) was amplified from synthesized genes and inserted into $\lambda_{\text {ARS1 }}$ DNA with Xhol and Nhel using the same protocol as described above.

DNA for bulk experiments

To generate the 601ARS1 DNA used for the restriction enzyme accessibility assay, a 372-bp DNA template 
CGGGGGACAGCGCGTACGTGCGTTTAAGCGGTGCTAGAGCTGTCTACGACCAATTGAGCGGCCTCGGCACCGGG ATTCTCCAGAAAATAGCAAATTTCGTCAAAAATGCTAAGAAATAGGTTATTACTGAGTAGTATTTATTTAAGTAT TGTTTGTGCACTTGCCTGCAGGCCTTTTGAAAAGCAAGCATAAAAGATCTAAACATAAAATCTGTAAAATAACA AGATGTAAAGATAATGCTAAATCATTTGGCTTTTTGATTGATTGTGCTAGCATATTAGCTAAAACTAAAAGTGGT; 601 sequence in italics; ARS1 underlined) was made by PCR using a primer with a primary amine group at its 3 ' terminus. The PCR products were purified on a Mono Q column (GE Healthcare) followed by ethanol precipitation. For fluorescent labeling, the DNA was mixed with Cy5 NHS ester (GE Healthcare) at room temperature for $2 \mathrm{~h}$. Free dyes were subsequently removed by a Sephadex G-25 column (GE Healthcare).

\section{Single-molecule experiments}

\section{Data acquisition}

Single-molecule experiments were performed at room temperature on a LUMICKS C-Trap instrument as previously described (25). Laminar-flow-separated channels 1-3 were used to form DNA tethers between two 4.35- $\mu \mathrm{m}$ streptavidin-coated polystyrene beads (Spherotech). Channels 4 and 5 served as protein loading and imaging channels. A488, Cy3, and Cy5/LD650 fluorophores were excited by 488 $\mathrm{nm}, 532 \mathrm{~nm}$ and $638 \mathrm{~nm}$ laser lines, respectively. Kymographs were generated via confocal line scanning through the center of the two beads.

\section{Nucleosome assembly in situ}

Optical traps tethering a single DNA were moved to a channel containing $1 \mathrm{nM}$ of fluorescently labeled histone octamers and $2 \mathrm{nM}$ Nap1 in HR buffer [30 mM Tris-OAc pH 7.5, $20 \mathrm{mM} \mathrm{Mg}(\mathrm{OAc})_{2}, 50 \mathrm{mM} \mathrm{KCl,} 1$ $\mathrm{mM} \mathrm{DTT}, 40 \mu \mathrm{g} / \mathrm{mL} \mathrm{BSA}$ ], and incubated under a tension below $1 \mathrm{pN}$ until a few fluorescent spots were seen. The tether was then moved to channel 3 containing $0.5 \mathrm{mg} / \mathrm{mL}$ salmon sperm DNA (Thermo Fisher) in HR buffer. A microfluidic flow was turned on for 1 min to gently remove free histones and free Nap1.

\section{Visualization of ORC}

Optical traps tethering a single non-nucleosomal DNA or nucleosomal DNA were moved to a separate channel containing $2 \mathrm{nM}$ Cy3- or LD650-ORC and $20 \mathrm{nM}$ Cdc6 in an imaging buffer containing $25 \mathrm{mM}$ Tris-OAc pH 7.5, 5\% glycerol, 40 mg/mL BSA, 3 mM DTT, $2 \mathrm{mM}$ TCEP, $0.1 \mathrm{mM}$ EDTA, $10 \mathrm{mM} \mathrm{Mg}(\mathrm{OAc})_{2}$, $50 \mathrm{mM}$ potassium glutamate, and $2.5 \mathrm{mM}$ ATP. The imaging buffer was supplemented with an ATPregeneration system $[60 \mathrm{mg} / \mathrm{mL}$ creatine phosphokinase (Sigma) and $20 \mathrm{mM}$ phosphocreatine (Sigma)], a triplet-state quenching cocktail [1 mM cyclooctatetraene (Sigma), 1 mM 4-nitrobenzyl alcohol (Sigma) and $1 \mathrm{mM}$ Trolox (Sigma)], as well as an oxygen scavenging system [10 $\mathrm{nM}$ protocatechuate-3,4-dioxygenase (Sigma) and $2.5 \mathrm{mM}$ protocatechuic acid (Sigma)]. The kymograph was typically followed for $10 \mathrm{~min}$.

\section{Visualization of MCM}

For two-color experiments (MCM and nucleosomes), a tethered nucleosomal DNA loaded with Cy3labeled octamers was moved to a channel containing $10 \mathrm{nM}$ LD650-MCM and 14 nM Cdt1, with or without $8 \mathrm{nM}$ ORC and $20 \mathrm{nM} \mathrm{Cdc6}$, in the imaging buffer described above in the presence of $5 \mathrm{mM}$ ATP. For three-color experiments (ORC, MCM and nucleosomes), 10 nM A488-MCM, 14 nM Cdt1, 2 nM LD650-ORC and 20 nM Cdc6 were used. For MCM DH loading experiments, a tethered DNA was moved 
to a channel containing $5 \mathrm{nM}$ Cy3-MCM, $5 \mathrm{nM}$ LD650-MCM, $8 \mathrm{nM}$ ORC, $20 \mathrm{nM}$ Cdc6 and 5 mM ATP. To visualize salt stability of MCMs, the tether was relocated to a channel containing $25 \mathrm{mM}$ Tris-OAc $\mathrm{pH}$ 7.5, 5\% glycerol, $40 \mu \mathrm{g} / \mathrm{mL}$ BSA, $3 \mathrm{mM}$ DTT, $2 \mathrm{mM}$ TCEP, $0.1 \mathrm{mM}$ EDTA, $10 \mathrm{mM} \mathrm{Mg}(\mathrm{OAc})_{2}, 300 \mathrm{mM}$ potassium glutamate and $5 \mathrm{mM}$ ATP.

\section{Data analysis}

Single-molecule force and fluorescence data from the .h5 files generated from C-Trap experiments were analyzed using tools in the lumicks.pylake Python library supplemented with other Python modules in a custom GUI Python script titled "C-Trap .h5 File Visualization GUI" (https://harbor.lumicks.com/single-script/c5b103a4-0804-4b06-95d3-20a08d65768f), which was written to extract confocal images and traces.

\section{Restriction enzyme accessibility assay}

Nucleosomes were positioned on Cy5-labeled 372-bp 601ARS1 DNA by salt dialysis as previously described (46). Yeast ISW1a was purified from yeast as previously described (49). To conduct the restriction enzyme accessibility assay, $2 \mathrm{nM}$ of nucleosomal DNA or non-nucleosomal DNA was incubated in digestion buffer [50 mM KOAc, $20 \mathrm{mM}$ Tris-OAc, $10 \mathrm{mM} \mathrm{Mg}(\mathrm{OAc})_{2}, 100 \mu \mathrm{g} / \mathrm{mL} \mathrm{BSA} \mathrm{pH}$ 7.9] with ATP (5 mM for ORC; 2 mM for ISW1a), the remodeler (190 nM Orc1-6/500 nM Cdc6/100 nM Nap1 for ORC, $2 \mathrm{nM}$ for ISW1a), and the restriction enzyme Banl ( $2 \mathrm{U} / \mu \mathrm{L}$ ) or BsiWI $(2 \mathrm{U} / \mu \mathrm{L})$ (New England BioLabs). Reactions were performed at $30^{\circ} \mathrm{C}$ for $2 \mathrm{~h}$ and quenched using $1.5 \times$ volume of stop buffer containing $20 \mathrm{mM}$ Tris pH 7.5, 2\% SDS, $50 \mathrm{mM}$ EDTA and $40 \mathrm{U} / \mathrm{mL}$ proteinase $\mathrm{K}$ (New England BioLabs) at $37^{\circ} \mathrm{C}$ for $1 \mathrm{~h}$, followed by phenol chloroform extraction and ethanol precipitation of the DNA. The air-dried pellets were resuspended in $20 \mu \mathrm{L} 5 \%$ glycerol and run on a $5 \%$ native polyacrylamide gel $(0.5 \times \mathrm{TBE})$ at $110 \mathrm{~V}$ for $50 \mathrm{~min}$. The gel was scanned by a Typhoon FLA 7000 gel imager (GE Healthcare). Band intensities were extracted by Fiji (50).

\section{Genomic data analysis}

To identify the genome-wide ORC binding sites, we downloaded Orc1 ChIP-seq data from Eaton et al (17) (SRX016027), aligned to the yeast genome (version Scer3) with bowtie2, and used MACS2 to call peaks (threshold: effective $P$ value 0.01). 1920 peaks were identified in total. All the peaks were resized to $200 \mathrm{bp}$ ( $\pm 100 \mathrm{bp}$ from the center point) and ranked based on the area underneath the curve. We assigned the top-ranked 400 peaks as "strong" Orc1 binding sites (the original Eaton et al paper used very stringent criteria and only identified 267 peaks). The peaks ranked from 401 to 1000 represent "weak" Orc1 binding sites or false positives, and were used as control. The bottom-ranked (1001-1920) peaks were discarded.

To investigate the nucleosome composition near Orc1 sites, we analyzed the MNase-histone ChIP-seq data in Chereji et al (29). In this dataset, the MNase-seq data ("input") reflect the degree of protection against micrococcal nuclease digestion; the subsequent H2B/H4 ChIP-seq data ("IP"), divided by the input, reflect the level of $\mathrm{H} 2 \mathrm{~B}$ or $\mathrm{H} 4$ in the protected particles. We used "multicovbed" program to calculate the input and IP signals over the sorted Orc1 sites. We also generated 10,000 random regions in the genome with $200 \mathrm{bp}$ in size, did the same IP/input calculation, and used this value to normalize the histone data. The original data were obtained with different strengths of MNase digestion (50U, 200U, etc.). The IP/input values over Orc1 sites are similar with $50 \mathrm{U}$ or $200 \mathrm{U}$ treatment. 
bioRxiv preprint doi: https://doi.org/10.1101/2021.08.17.456647; this version posted August 18, 2021. The copyright holder for this preprint (which was not certified by peer review) is the author/funder, who has granted bioRxiv a license to display the preprint in perpetuity. It is made available under aCC-BY-NC-ND 4.0 International license.

The $\mathrm{H} 2 \mathrm{~B}$ results in this paper were averaged between one $50 \mathrm{U}$ and one $200 \mathrm{U}$ dataset (the original paper only had one set each), and the $\mathrm{H} 4$ results were averaged between two $200 \mathrm{U}$ datasets.

\section{Statistical analysis}

Errors reported in this study represent the standard error of the mean (SEM). $P$ values were determined from two-tailed two-sample $t$ tests (ns, not significant; ${ }^{*} P<0.05 ;{ }^{* *} P<0.01$; ${ }^{* * *} P<0.001$; $* * * * P<0.0001)$. 


\section{Acknowledgments}

We thank X. Zhao (MSKCC) for critical reading of the manuscript, L. Langston, R. Mayle, G. Schauer, N. Yao, and D. Zhang in the O'Donnell laboratory for reagents, J. Watters in the Liu Laboratory for data analysis codes, and other members of the Liu and O'Donnell labs for discussions. L.B. is supported by National Institutes of Health (R01GM118682 \& R35GM139654). M.E.O. is supported by NIH (R01GM115809) and the Howard Hughes Medical Institute. S.Liu is supported by the Robertson Foundation, the Alfred P. Sloan Foundation, the Pershing Square Sohn Cancer Research Alliance, and an NIH Director's New Innovator Award (DP2HG010510).

\section{Contributions}

S.Liu and M.E.O. oversaw the project. M.R.W. prepared the DNA templates. M.R.W., O.Y. and S.Li prepared and labeled the replication proteins. S.Li prepared the nucleosome samples and performed the restriction enzyme accessibility assay. S.Li and M.R.W. performed single-molecule experiments and analyzed the data. L.B. performed the genomic data analysis. S.Liu, M.E.O., S.Li and L.B. wrote the manuscript.

\section{Competing interests}

The authors declare no competing interests. 


\section{REFERENCES}

1. S. P. Bell, K. Labib, Chromosome Duplication in Saccharomyces cerevisiae. Genetics 203, 1027-1067 (2016).

2. F. Bleichert, M. R. Botchan, J. M. Berger, Mechanisms for initiating cellular DNA replication. Science 355, (2017).

3. N. Rhind, D. M. Gilbert, DNA replication timing. Cold Spring Harb Perspect Biol 5, a010132 (2013).

4. S. P. Bell, B. Stillman, ATP-dependent recognition of eukaryotic origins of DNA replication by a multiprotein complex. Nature 357, 128-134 (1992).

5. B. P. Duncker, I. N. Chesnokov, B. J. McConkey, The origin recognition complex protein family. Genome Biol 10, 214 (2009).

6. C. Evrin et al., A double-hexameric MCM2-7 complex is loaded onto origin DNA during licensing of eukaryotic DNA replication. Proc Natl Acad Sci U S A 106, 20240-20245 (2009).

7. D. Remus et al., Concerted loading of $\mathrm{Mcm} 2-7$ double hexamers around DNA during DNA replication origin licensing. Cell 139, 719-730 (2009).

8. M. N. Prioleau, D. M. MacAlpine, DNA replication origins-where do we begin? Genes Dev 30, 1683-1697 (2016).

9. J. T. Yeeles, T. D. Deegan, A. Janska, A. Early, J. F. Diffley, Regulated eukaryotic DNA replication origin firing with purified proteins. Nature 519, 431-435 (2015).

10. C. S. K. Lee et al., Humanizing the yeast origin recognition complex. Nat Commun 12, 33 (2021).

11. O. K. Smith, M. I. Aladjem, Chromatin structure and replication origins: determinants of chromosome replication and nuclear organization. J Mol Biol 426, 3330-3341 (2014).

12. J. M. Bellush, I. Whitehouse, DNA replication through a chromatin environment. Philos Trans R Soc Lond B Biol Sci 372, (2017).

13. S. Devbhandari, J. Jiang, C. Kumar, I. Whitehouse, D. Remus, Chromatin Constrains the Initiation and Elongation of DNA Replication. Mol Cell 65, 131 (2017).

14. I. F. Azmi et al., Nucleosomes influence multiple steps during replication initiation. Elife 6, (2017).

15. C. F. Kurat, J. T. P. Yeeles, H. Patel, A. Early, J. F. X. Diffley, Chromatin Controls DNA Replication Origin Selection, Lagging-Strand Synthesis, and Replication Fork Rates. Mol Cell 65, 117-130 (2017).

16. R. T. Simpson, Nucleosome positioning can affect the function of a cis-acting DNA element in vivo. Nature 343, 387-389 (1990).

17. M. L. Eaton, K. Galani, S. Kang, S. P. Bell, D. M. MacAlpine, Conserved nucleosome positioning defines replication origins. Genes Dev 24, 748-753 (2010).

18. J. R. Lipford, S. P. Bell, Nucleosomes positioned by ORC facilitate the initiation of DNA replication. Mol Cell 7, 21-30 (2001).

19. J. A. Belsky, H. K. MacAlpine, Y. Lubelsky, A. J. Hartemink, D. M. MacAlpine, Genome-wide chromatin footprinting reveals changes in replication origin architecture induced by preRC assembly. Genes Dev 29, 212-224 (2015).

20. S. Ticau, L. J. Friedman, N. A. Ivica, J. Gelles, S. P. Bell, Single-molecule studies of origin licensing reveal mechanisms ensuring bidirectional helicase loading. Cell 161, 513-525 (2015). 
21. D. Duzdevich et al., The dynamics of eukaryotic replication initiation: origin specificity, licensing, and firing at the single-molecule level. Mol Cell 58, 483-494 (2015).

22. H. Sanchez et al., DNA replication origins retain mobile licensing proteins. Nat Commun 12, 1908 (2021).

23. D. T. Stinchcomb, K. Struhl, R. W. Davis, Isolation and characterisation of a yeast chromosomal replicator. Nature 282, 39-43 (1979).

24. A. Candelli, G. J. Wuite, E. J. Peterman, Combining optical trapping, fluorescence microscopy and micro-fluidics for single molecule studies of DNA-protein interactions. Phys Chem Chem Phys 13, 7263-7272 (2011).

25. M. R. Wasserman, G. D. Schauer, M. E. O'Donnell, S. Liu, Replication Fork Activation Is Enabled by a Single-Stranded DNA Gate in CMG Helicase. Cell 178, 600-611 (2019).

26. G. Coster, J. F. X. Diffley, Bidirectional eukaryotic DNA replication is established by quasisymmetrical helicase loading. Science 357, 314-318 (2017).

27. J. B. Crickard, C. J. Moevus, Y. Kwon, P. Sung, E. C. Greene, Rad54 Drives ATP HydrolysisDependent DNA Sequence Alignment during Homologous Recombination. Cell 181, 13801394 (2020).

28. C. Speck, Z. Chen, H. Li, B. Stillman, ATPase-dependent cooperative binding of ORC and Cdc6 to origin DNA. Nat Struct Mol Biol 12, 965-971 (2005).

29. R. V. Chereji, J. Ocampo, D. J. Clark, MNase-Sensitive Complexes in Yeast: Nucleosomes and Non-histone Barriers. Mol Cell 65, 565-577 (2017).

30. N. Li et al., Structure of the origin recognition complex bound to DNA replication origin. Nature 559, 217-222 (2018).

31. X. Feng et al., The structure of ORC-Cdc6 on an origin DNA reveals the mechanism of ORC activation by the replication initiator Cdc6. Nat Commun 12, 3883 (2021).

32. C. A. Nieduszynski, Y. Knox, A. D. Donaldson, Genome-wide identification of replication origins in yeast by comparative genomics. Genes Dev 20, 1874-1879 (2006).

33. D. M. MacAlpine, G. Almouzni, Chromatin and DNA replication. Cold Spring Harb Perspect Biol 5, a010207 (2013).

34. D. M. Gilbert, In search of the holy replicator. Nat Rev Mol Cell Biol 5, 848-855 (2004).

35. M. Fragkos, O. Ganier, P. Coulombe, M. Mechali, DNA replication origin activation in space and time. Nat Rev Mol Cell Biol 16, 360-374 (2015).

36. M. I. Aladjem, C. E. Redon, Order from clutter: selective interactions at mammalian replication origins. Nat Rev Genet 18, 101-116 (2017).

37. A. J. Kuo et al., The BAH domain of ORC1 links H4K20me2 to DNA replication licensing and Meier-Gorlin syndrome. Nature 484, 115-119 (2012).

38. P. De Ioannes et al., Structure and function of the Orc1 BAH-nucleosome complex. Nat Commun 10, 2894 (2019).

39. K. Hizume, M. Yagura, H. Araki, Concerted interaction between origin recognition complex (ORC), nucleosomes and replication origin DNA ensures stable ORC-origin binding. Genes Cells 18, 764-779 (2013).

40. M. J. Rossi et al., A high-resolution protein architecture of the budding yeast genome. Nature 592, 309-314 (2021).

41. H. Long et al., H2A.Z facilitates licensing and activation of early replication origins. Nature 577, 576-581 (2020).

42. J. F. Diffley, Quality control in the initiation of eukaryotic DNA replication. Philos Trans $R$ Soc Lond B Biol Sci 366, 3545-3553 (2011). 
43. Z. Zhou et al., Genetically encoded short peptide tags for orthogonal protein labeling by Sfp and AcpS phosphopantetheinyl transferases. ACS Chem Biol 2, 337-346 (2007).

44. R. E. Georgescu et al., Mechanism of asymmetric polymerase assembly at the eukaryotic replication fork. Nat Struct Mol Biol 21, 664-670 (2014).

45. A. Johnson et al., Reconstitution of heterochromatin-dependent transcriptional gene silencing. Mol Cell 35, 769-781 (2009).

46. S. Li, E. B. Zheng, L. Zhao, S. Liu, Nonreciprocal and Conditional Cooperativity Directs the Pioneer Activity of Pluripotency Transcription Factors. Cell Rep 28, 2689-2703 (2019).

47. Y. Marahrens, B. Stillman, A yeast chromosomal origin of DNA replication defined by multiple functional elements. Science 255, 817-823 (1992).

48. T. J. Lockett, A bacteriophage lambda DNA purification procedure suitable for the analysis of DNA from either large or multiple small lysates. Anal Biochem 185, 230-234 (1990).

49. J. C. Vary, Jr., T. G. Fazzio, T. Tsukiyama, Assembly of yeast chromatin using ISWI complexes. Methods Enzymol 375, 88-102 (2004).

50. J. Schindelin et al., Fiji: an open-source platform for biological-image analysis. Nat Methods 9, 676-682 (2012).

51. I. Liachko, R. A. Youngblood, U. Keich, M. J. Dunham, High-resolution mapping, characterization, and optimization of autonomously replicating sequences in yeast. Genome Res 23, 698-704 (2013). 
A

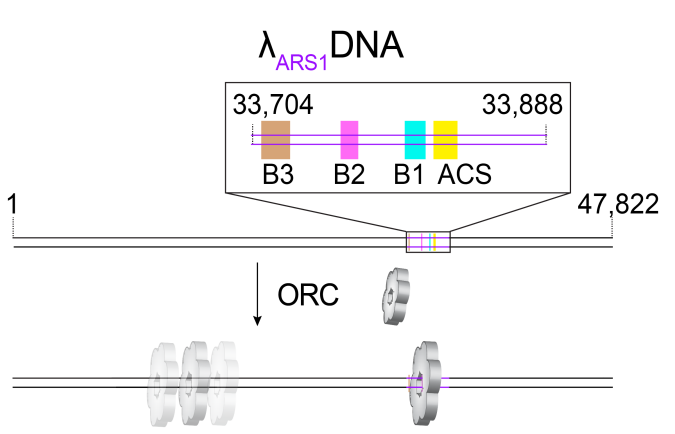

C

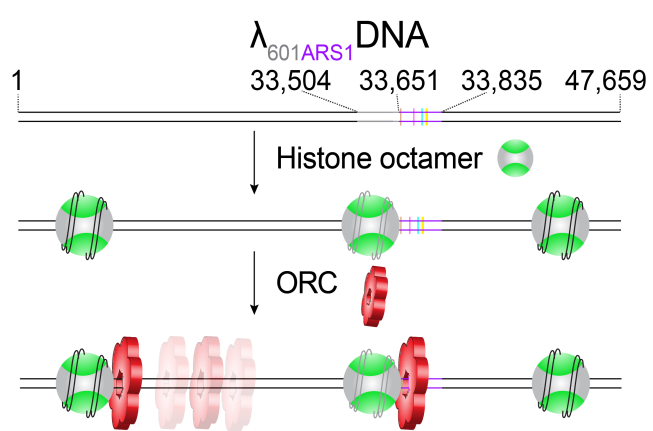

$E$

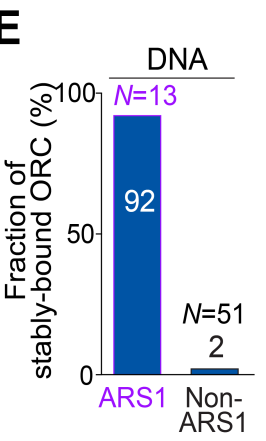

$\mathbf{F}$

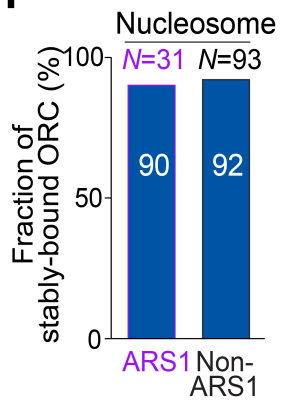

B

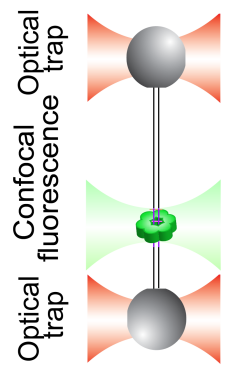

D

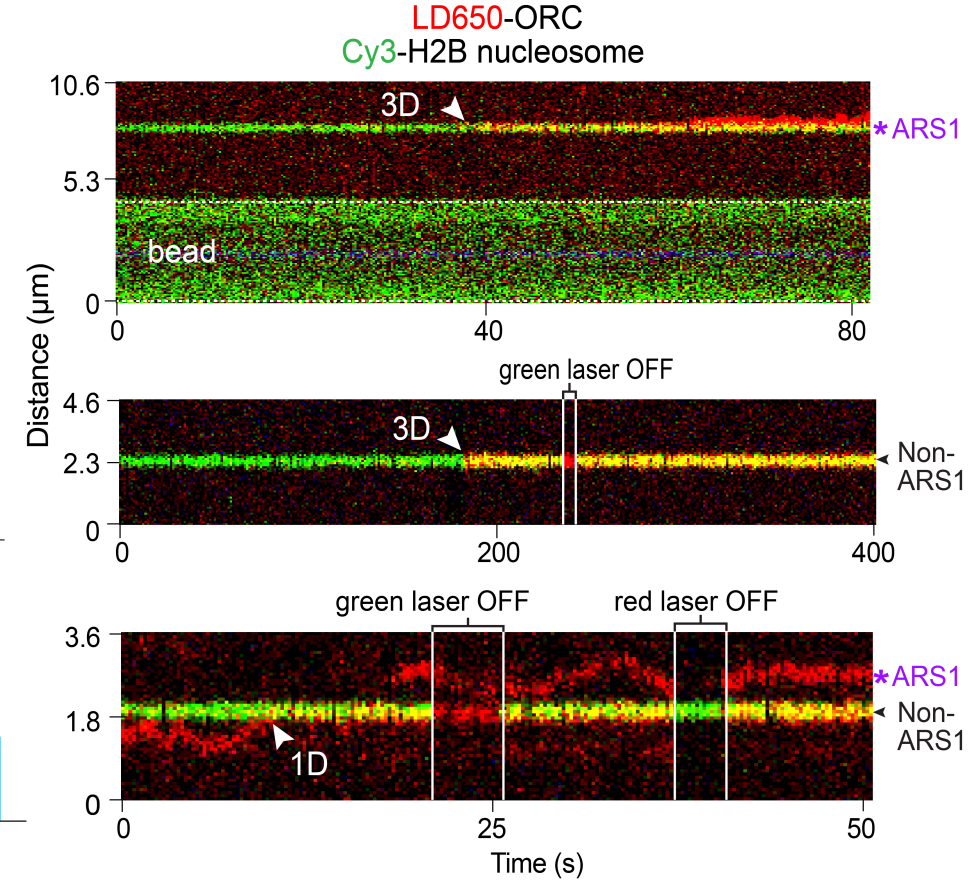

Figure 1. ORC searches and stably binds nucleosomes independently of the ARS element. (A) Cartoon of the $\lambda_{\text {ARS1 }}$ DNA template. The inserted ARS1 element is illustrated in the inset box. (B) (Left) Schematic of the optical tweezers setup combined with single-molecule confocal fluorescence microscopy. (Right) A representative kymograph showing the dynamics of individual Cy3-labeled ORC complexes on $\lambda_{\text {ARS1 } 1}$ DNA. The engineered ARS1 position is indicated.(C) Cartoon of the $\lambda_{601 A R S 1}$ DNA loaded with nucleosomes. (D) Three representative kymographs showing LD650-labeled ORC-Cdc6 (red) binding to a Cy3-labeled nucleosome (green) located at an ARS1 or non-ARS1 site. White arrows indicate the time when ORC arrived at the nucleosomal site via three-dimensional (3D) or onedimensional (1D) search. (E) Quantification of the fraction of ORC stably residing at the ARS1 site and non-ARS1 sites on the non-nucleosomal DNA template. (F) Quantification of the fraction of ORC stably bound to nucleosomes located at either the ARS1 site or non-ARS1 sites. (G) Fraction of ORC targeting a nucleosome by a 3D or 1D search mode. $N$ indicates the number of analyzed events. 
A

Unlabeled ORC, labeled nucleosome and MCM

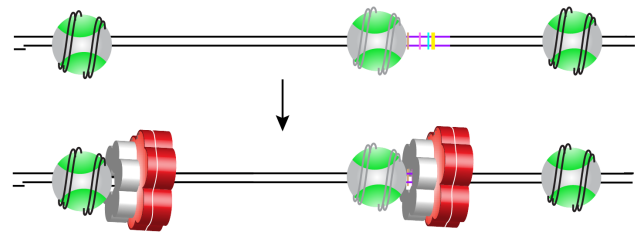

B

Су3-H2A

LD650-MCM
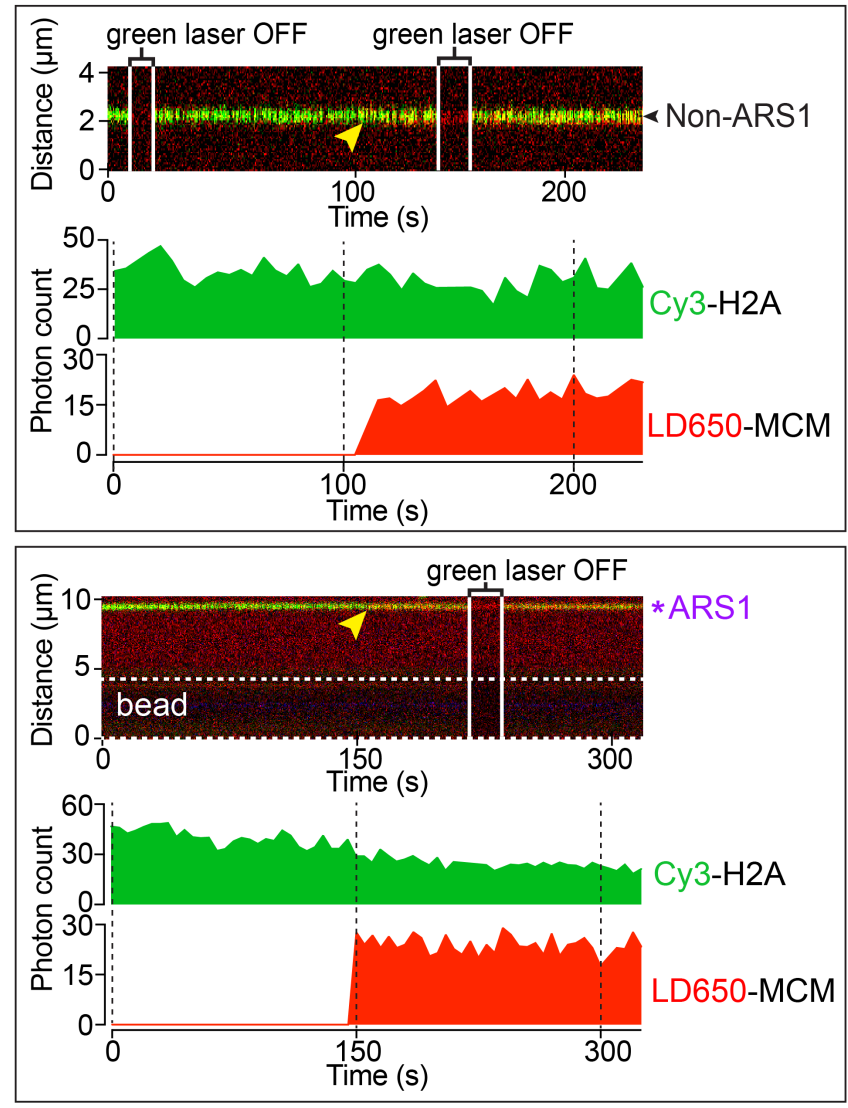

C

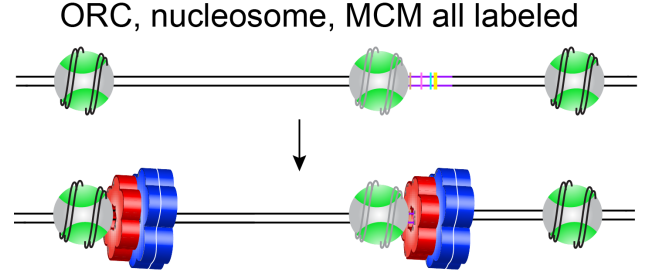

D
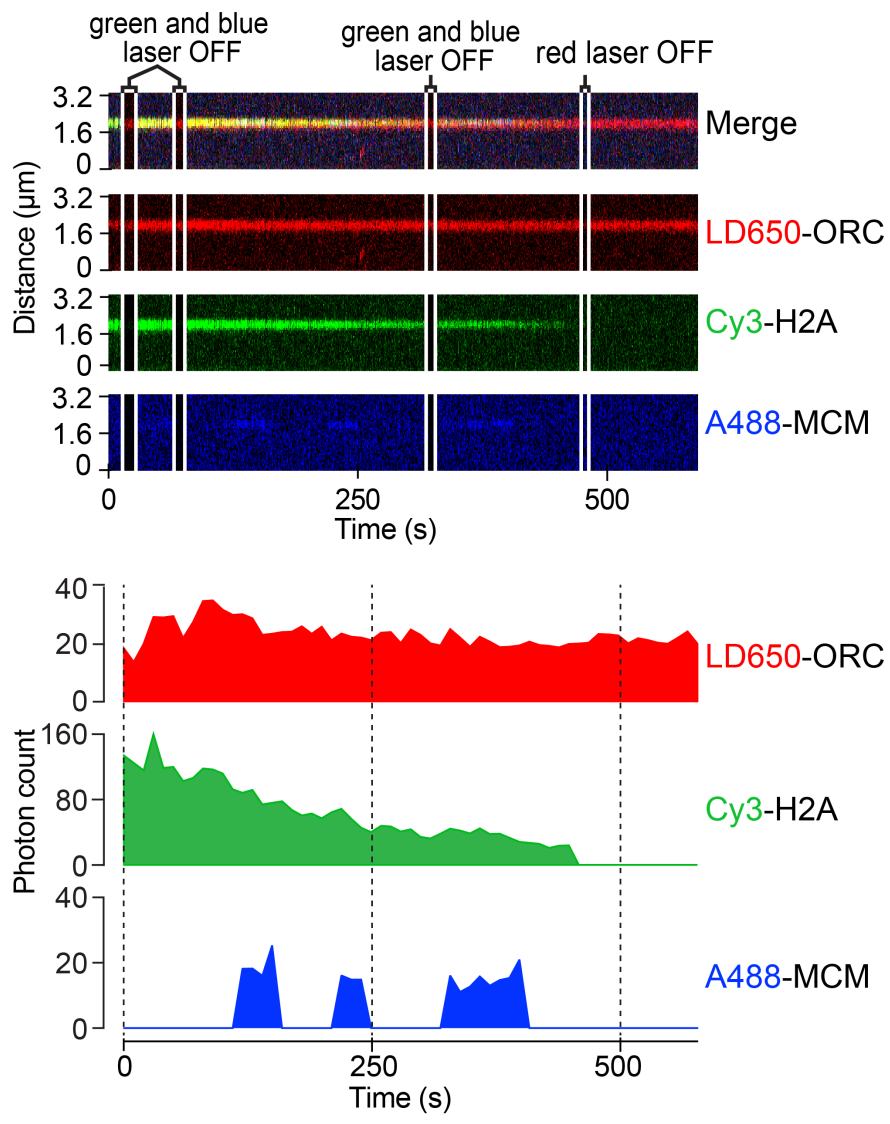

Figure 2. ORC interaction with nucleosomes leads to MCM loading. (A) Cartoon of the pre-RC assembly experiment using $\lambda_{601 A R S 1}$ DNA, Cy3-labeled nucleosomes, LD650-labeled MCM and unlabeled ORC. (B) Two representative kymographs showing an MCM (red) being loaded to a nucleosome (green) at a non-ARS1 (Top) or ARS1 (Bottom) site in the presence of ORC. The red and green fluorescence intensities at the nucleosome position as a function of time are shown below the corresponding kymograph. Yellow arrows indicate the time when the MCM fluorescence signal appeared at the nucleosomal site. (C) Cartoon of the three-color experiment using Cy3-labeled nucleosomes, A488labeled MCM and LD650-labeled ORC to monitor pre-RC assembly. (D) A representative kymograph showing colocalization of the nucleosome (green), ORC (red) and MCM (blue). The corresponding fluorescence intensities at the nucleosome position are shown below. 
A
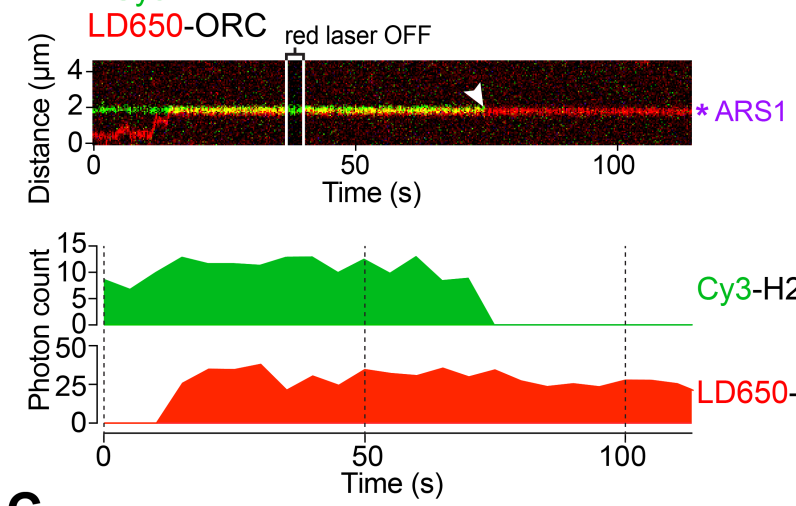

C

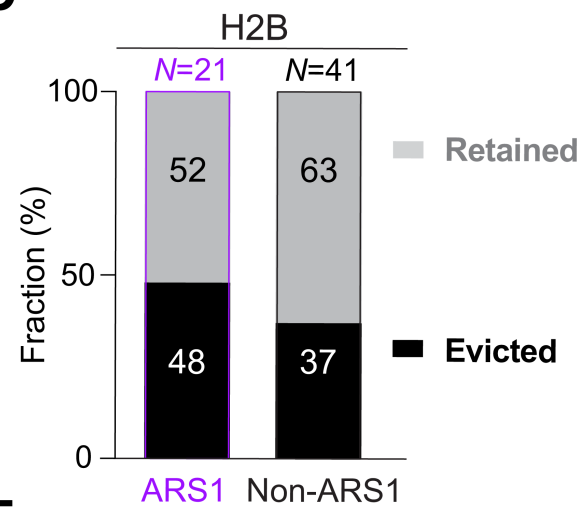

E

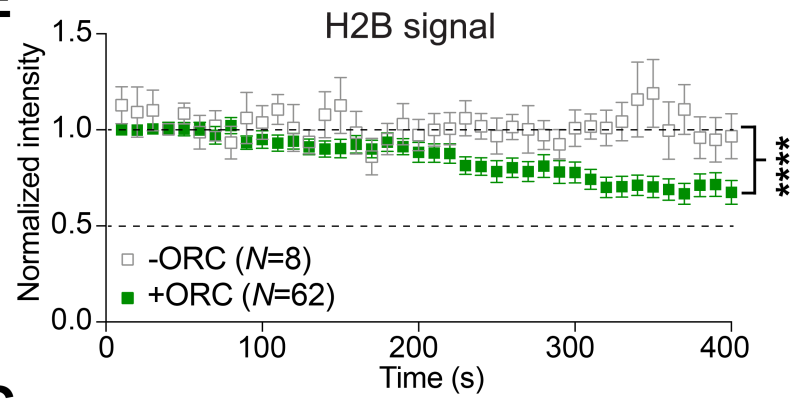

G

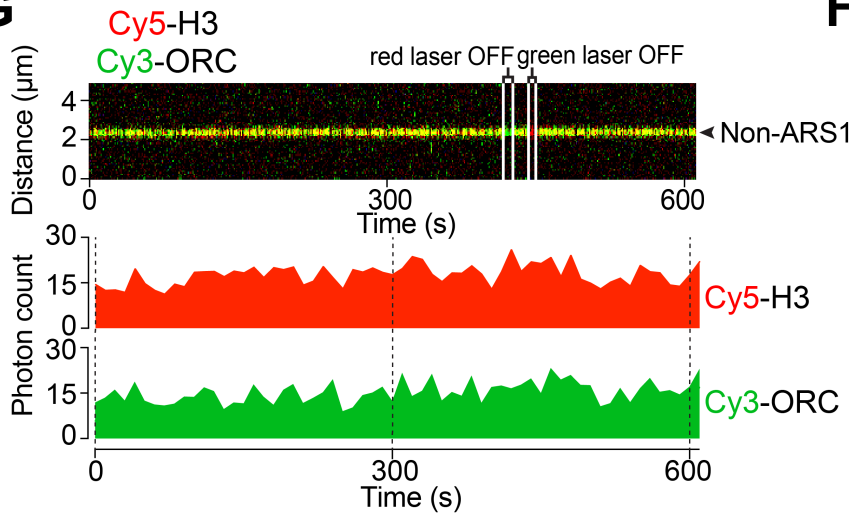

Су3-H2B

L650-ORC
B Cy3-H2B

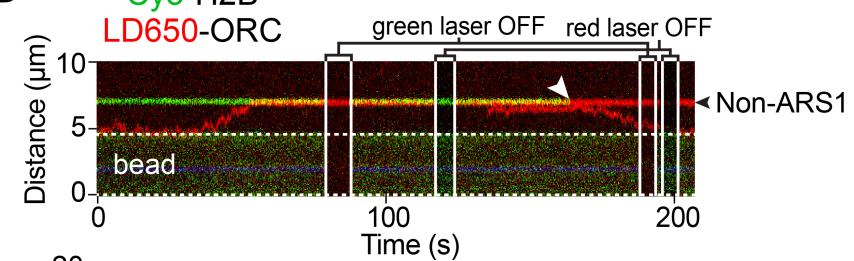

\section{D}
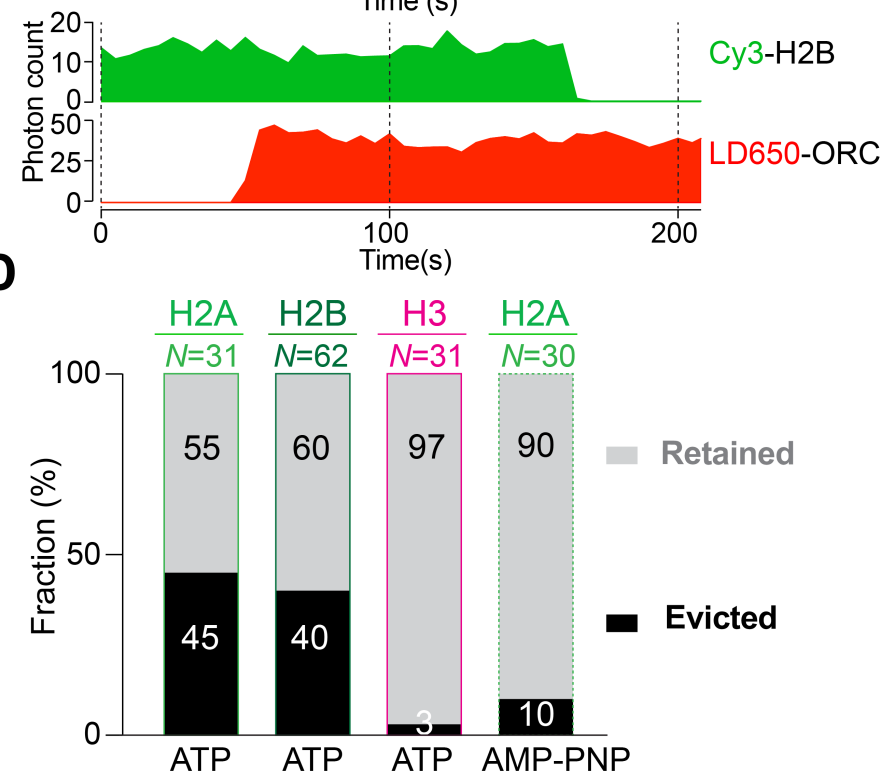

$\mathbf{F}$

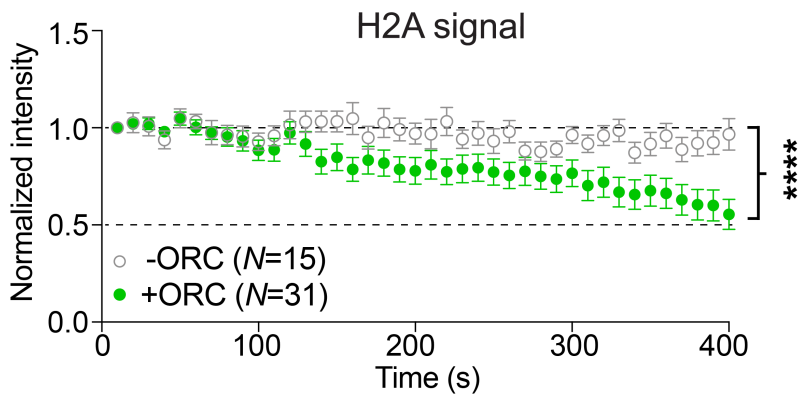

H

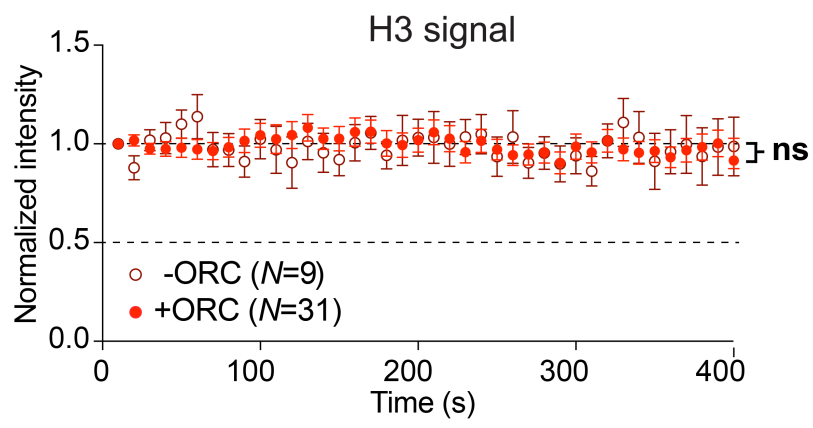

Figure 3. ORC selectively evicts H2A-H2B from the nucleosome. (A) (Top) A representative kymograph showing disappearance of the $\mathrm{H} 2 \mathrm{~B}$ fluorescence signal (green) after ORC (red) arrived at a nucleosome at the ARS1 site. (Bottom) The corresponding Cy3-H2B and LD650-ORC fluorescence intensities at the 
nucleosome position. (B) A representative kymograph (Top) and the corresponding fluorescence intensities (Bottom) showing H2B eviction induced by ORC-nucleosome interaction at a non-ARS1 site. White arrows indicate the time when $\mathrm{H} 2 \mathrm{~B}$ was evicted. (C) Fraction of histone $\mathrm{H} 2 \mathrm{~B}$ evicted versus retained after ORC binding to an ARS1 or non-ARS1 nucleosome. (D) Fraction of $\mathrm{H} 2 \mathrm{~A}, \mathrm{H} 2 \mathrm{~B}$, or $\mathrm{H} 3$ evicted versus retained after ORC binding to a nucleosomal site in the presence of $A T P$, or in the presence of AMPPNP in the case of $\mathrm{H} 2 \mathrm{~A}$. (E) Normalized $\mathrm{Cy} 3-\mathrm{H} 2 \mathrm{~B}$ intensity as a function of time averaged over many nucleosomal sites in the absence (open squares) or presence (green squares) of ORC. (F) Normalized average $\mathrm{Cy} 3-\mathrm{H} 2 \mathrm{~A}$ intensity as a function of time in the absence (open circles) or presence (green circles) of ORC. (G) A representative kymograph (Top) and the corresponding fluorescence intensities of $\mathrm{Cy} 5-\mathrm{H} 3$ and $\mathrm{Cy} 3-\mathrm{ORC}$ (Bottom) showing sustained $\mathrm{H} 3$ signal at the nucleosomal site despite a colocalized ORC. (H) Normalized Cy5-H3 intensity as a function of time averaged over many nucleosomal sites in the absence (open circles) or presence (red circles) of ORC. $N$ indicates the number of analyzed events. Error bars represent SEM. 


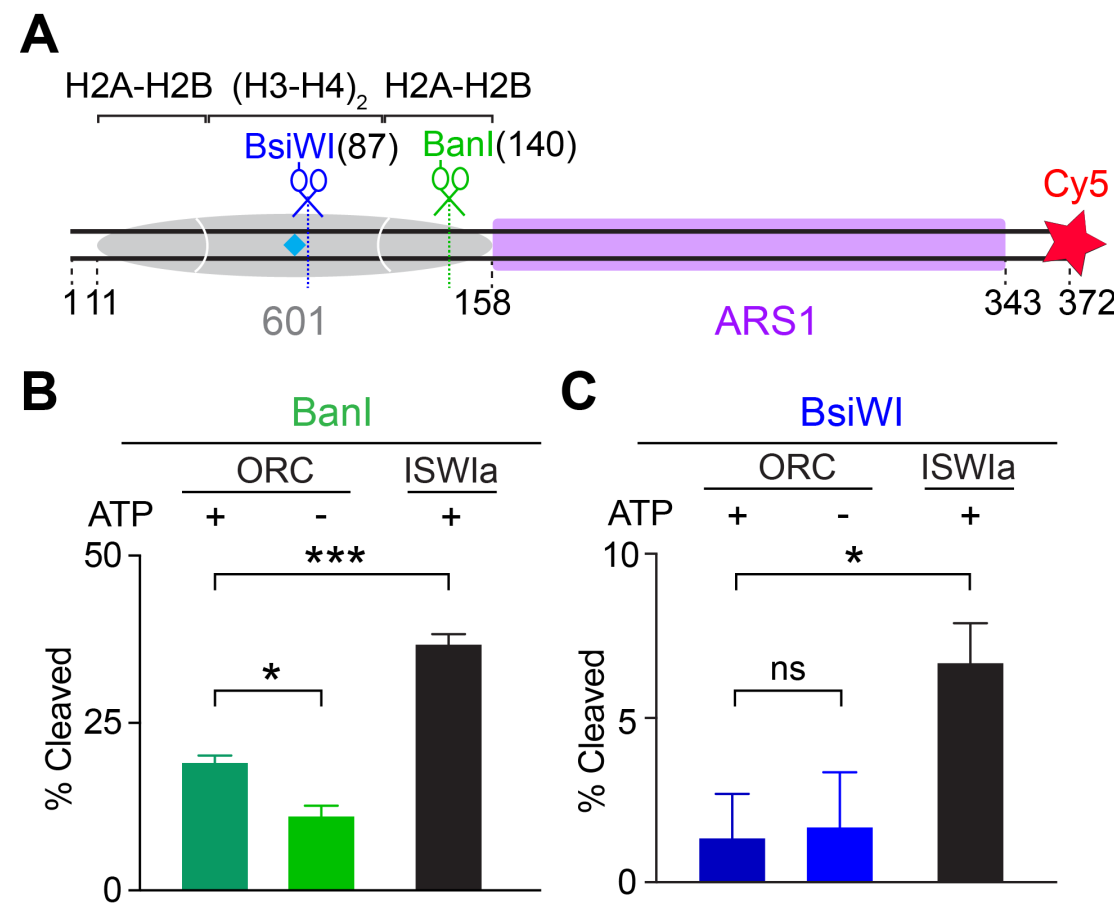

Figure 4. ORC changes the accessibility of nucleosomal DNA. (A) Schematic of end-labeled 601ARS1 nucleosomal DNA. The DNA segments protected by $\mathrm{H} 2 \mathrm{~A}-\mathrm{H} 2 \mathrm{~B}$ dimers and the $(\mathrm{H} 3-\mathrm{H} 4)_{2}$ tetramer, as well as the Banl and BsiWI restriction sites, are indicated. Cyan symbol indicates the nucleosome dyad position. (B) Results of restriction enzyme accessibility assay showing the fraction of 601ARS1 nucleosomal DNA cleaved by Banl when incubated with ORC-Cdc6 ( \pm ATP) or ISW1a. (C) Fraction of 601ARS1 nucleosomal DNA cleaved by BsiWI when incubated with ORC-Cdc6 ( \pm ATP) or ISW1a. Data are mean \pm SEM from three independent experiments. 


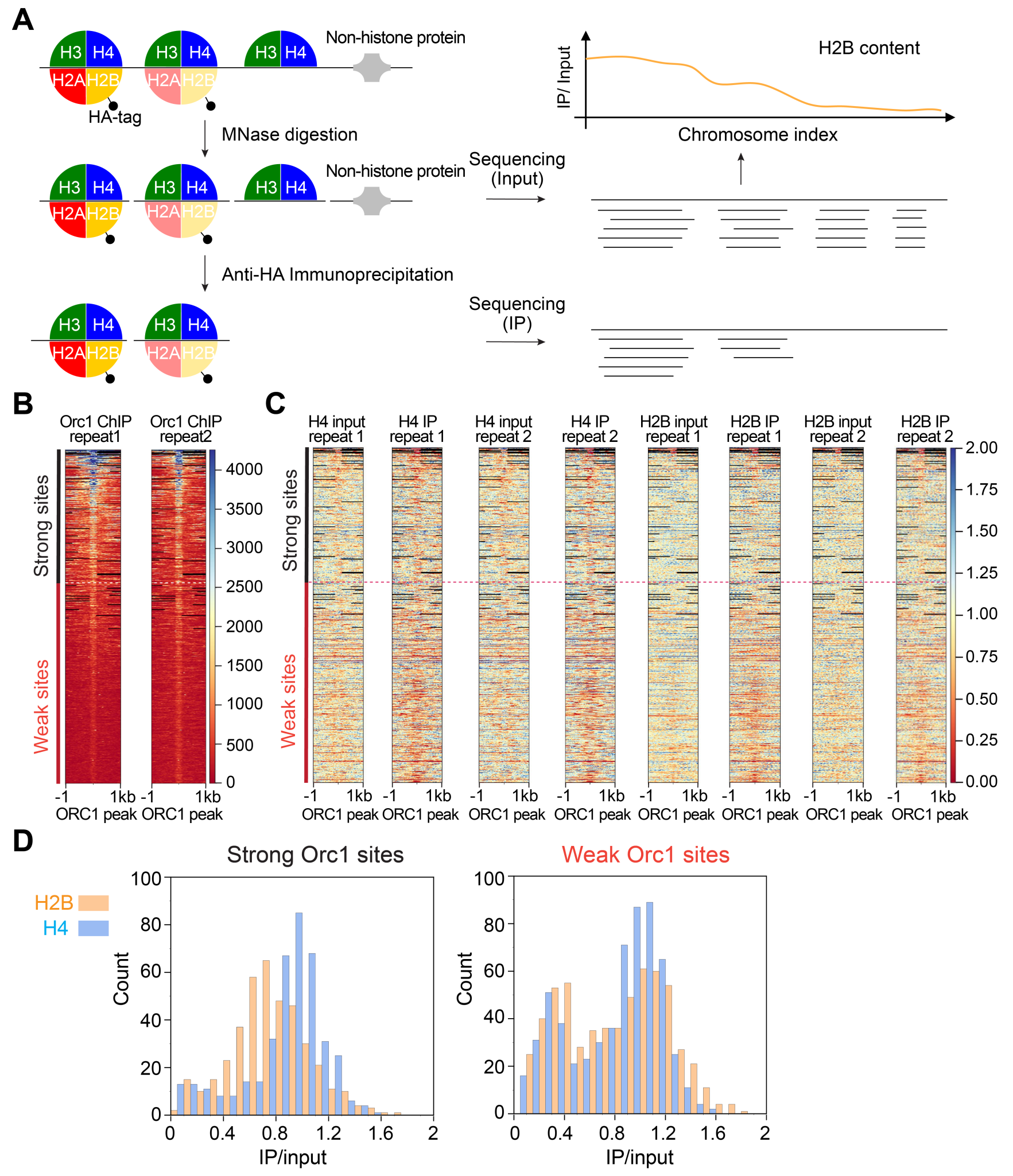

Figure 5. H2B is depleted at strong ORC binding sites genome-wide. (A) Schematic workflow of analyzing histone content at specific sites in the yeast genome. The diagram shows the situation where $\mathrm{H} 2 \mathrm{~B}$ is HA-tagged. The same procedure applies to HA-tagged H4. (B) Heatmap of the Orc1 ChIP-seq 
data (17). The heatmap is aligned at the center of Orc1 peaks and sorted based on the peak intensity (ranked 1-1,000 from top to bottom). The two panels represent biological replicates. (C) Heatmap of the H4/H2B MNase-ChIP-seq data (29) at the top 1,000 Orc1 sites. These heatmaps are aligned at the center of Orc1 peaks with the same rank order as in (B) Different panels represent two repeats of MNase-seq (input) and MNase-H4/H2B ChIP-seq (IP) signals. (D) Comparison of H2B and H4 content over genome-wide Orc1 binding sites. The Orc1 sites were ranked based on their ChIP-seq intensities and divided into strong and weak group. 


\section{A}
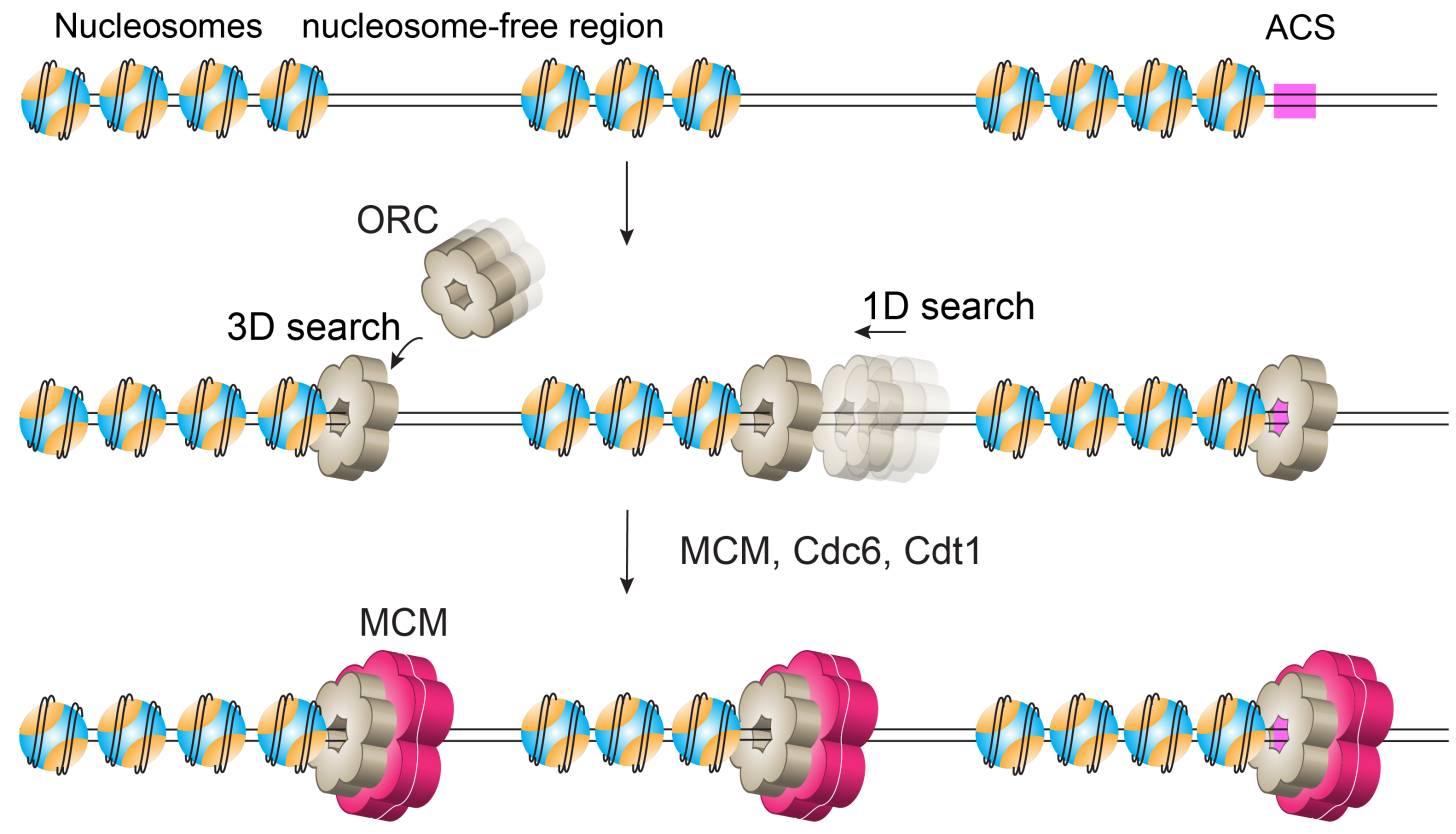

B

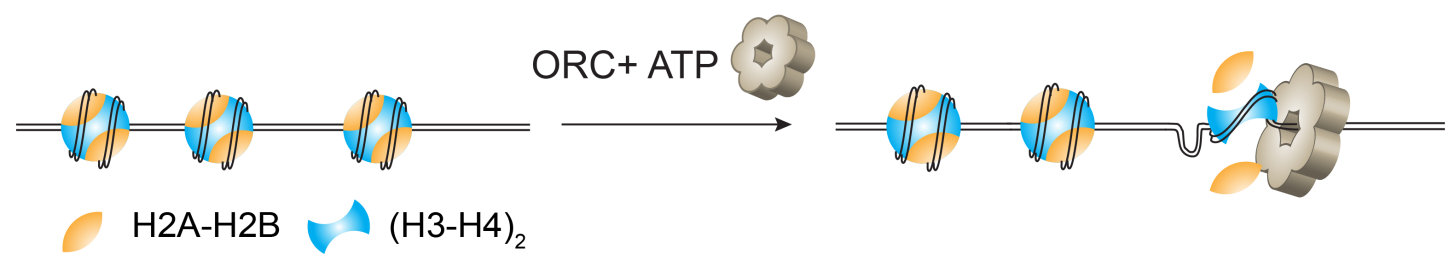

Figure 6. Model of ORC functioning in replication initiation and chromatin remodeling. (A) Model illustrating the process of ORC searching nucleosomes in a chromatinized genome, stably associating with them in the presence or absence of a nearby ACS motif, and loading MCM in conjunction with Cdc6 and Cdt1 to form pre-RC. (B) Model of ATP-dependent removal of H2A-H2B dimers from ORCassociated nucleosomes. 